\title{
Vertical Mixing, Energy, and the General Circulation of the Oceans
}

\author{
Carl Wunsch and Raffaele Ferrari \\ Department of Earth, Atmospheric, and Planetary Sciences, Massachusetts Institute of \\ Technology, Cambridge, Massachusetts 02139; email: cwunsch@mit.edu, \\ raffaelle@mit.edu
}

Key Words ocean circulation, ocean mixing, ocean circulation energy

- Abstract The coexistence in the deep ocean of a finite, stable stratification, a strong meridional overturning circulation, and mesoscale eddies raises complex questions concerning the circulation energetics. In particular, small-scale mixing processes are necessary to resupply the potential energy removed in the interior by the overturning and eddy-generating process. A number of lines of evidence, none complete, suggest that the oceanic general circulation, far from being a heat engine, is almost wholly governed by the forcing of the wind field and secondarily by deep water tides. In detail however, the budget of mechanical energy input into the ocean is poorly constrained. The now inescapable conclusion that over most of the ocean significant "vertical" mixing is confined to topographically complex boundary areas implies a potentially radically different interior circulation than is possible with uniform mixing. Whether ocean circulation models, either simple box or full numerical ones, neither explicitly accounting for the energy input into the system nor providing for spatial variability in the mixing, have any physical relevance under changed climate conditions is at issue.

\section{INTRODUCTION}

A feature strongly distinguishing ocean physics from that of the atmosphere is the nearly universal oceanic stable stratification. Apart from the very near-surface areas, only rarely and sporadically does one find statically neutral or unstable oceanic regions. When such regions do occur, they tend to last for hours at most, occupy lateral areas of a few kilometers, and have a wide range of vertical scales. Figure 1 displays a typical meridional density cross-section, and Figure 2 the buoyancy frequency,

$$
N(z)=\left(-\frac{g}{\sigma} \frac{\partial \sigma}{\partial z}\right)^{1 / 2}
$$




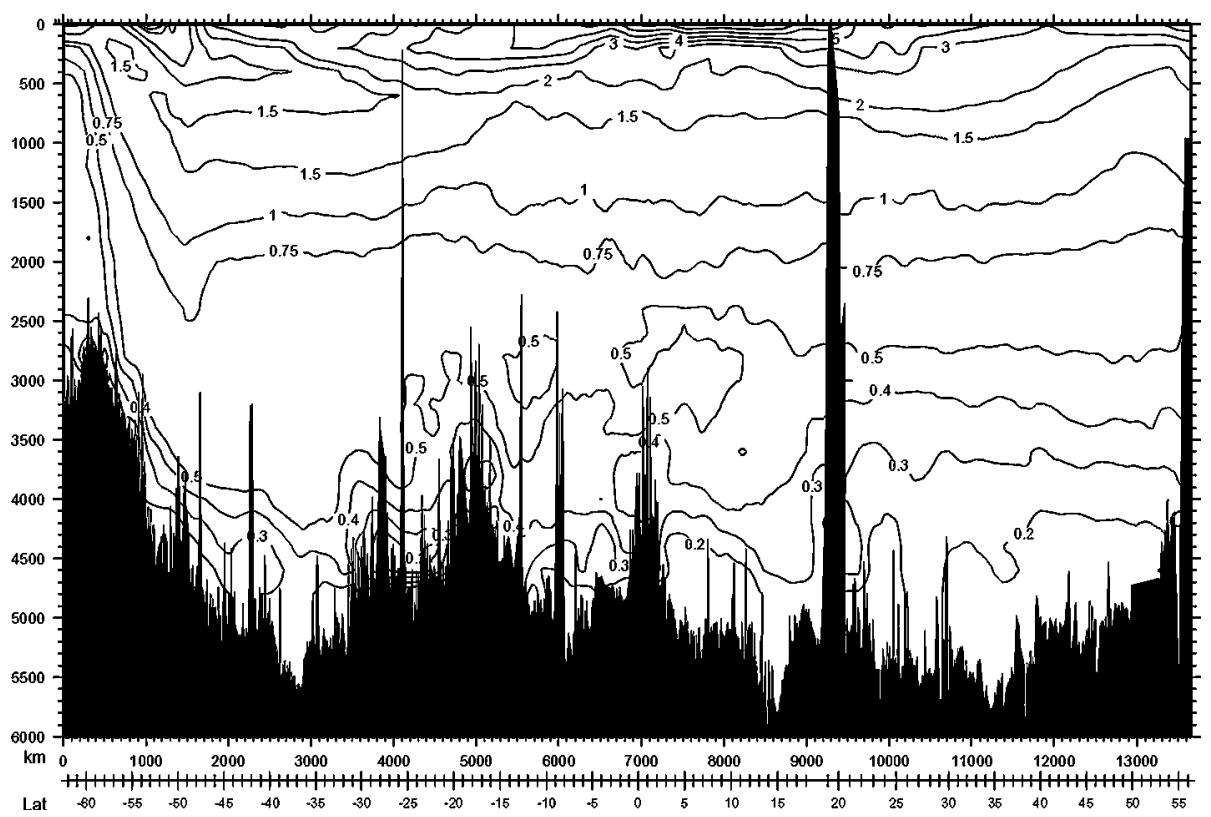

Figure 2 Buoyancy frequency (cycles/hour) corresponding to the density profile in Figure 1. Spatial smoothing removed what is otherwise an extremely noisy high wave-number jitter. The ratio $N / f \gg 1$, where $N, f$ are the buoyancy and Coriolis frequencies, shows that the abyssal stratification is of first-order importance.

Here $z$ is a local vertical coordinate, $\sigma$ is the potential density, ${ }^{1}$ and $g$ is local gravity. $N$ is a convenient measure of the degree of stratification. Corresponding periods $(2 \pi / N)$ range from about 10 minutes in the upper oceanic thermocline to a few hours in the least stratified parts of the abyss. The ratio $N / f$, where $f=2 \Omega \sin \phi$, is the Coriolis frequency with $\phi$ the latitude, measures the relative importance of stratification and of rotation. $N / f$ is almost always greater than 1 , and is typically of order 10 or more; the ocean abyss is dominated by its stratification.

Unlike the classic Rayleigh-Bénard convection, and the atmosphere, the ocean is heated and cooled at the surface. This geometry of buoyancy exchange has farreaching and unexpected consequences. One needs to consider moisture exchange too, but it does not change the picture. The simplest hypothesis about how such a system might work leads one to expect a very different oceanic stratification than is observed or what many theories suppose and we are led into questions of mixing

\footnotetext{
${ }^{1}$ Potential density is defined as the density attained by a water particle if taken isentropically to a fixed pressure (commonly 0 ). It is a useful quantity in oceanic studies because it eliminates in situ density variations due to compressibility that have no dynamical effect.
} 
and energetics. The focus here is on observations and a few theoretical constructs. For reasons of space, we omit a serious discussion of oceanic numerical general circulation models. Although such models are powerful tools for understanding the ocean, so many questions arise concerning model energy consistency and realism that their inclusion would greatly increase the length of this review. We use a few model results when no other evidence is available.

The diversity of material here is so great that within the Procrustean space limitations we rely heavily on existing reviews. Apologies are offered to the pioneers, whose work is slighted. New papers are appearing every month and this review is in danger of rapid obsolescence.

\section{THE STRATIFICATION}

\section{Observations}

In a few narrow, sporadic oceanic regions at high latitudes (see Warren 1981) near-surface fluid sometimes becomes sufficiently dense to be vertically unstable, sinking to the sea floor (see several chapters in Siedler et al. 2001). Fluid properties reaching the bottom are determined from a complex entrainment process (Price \& Baringer 1994). Although much is known about high latitude convection (Marshall $\&$ Schott 1999), little is understood of the physics that controls where, how often, and with what properties (depth, temperature, etc.) convection occurs.

For present purposes, it suffices that there are sources of fluid reaching to great depths, carrying near-surface properties, but mixed with entrained fluid on the way, and having comparatively high densities (low temperatures and high salinities). The great green "tongue," visible in Figure 1, is a symptom of fluid properties sinking to the bottom. The net mass flux in such plumes is poorly determined. Fluid is thought to reach the lowest $1000 \mathrm{~m}$ of ocean at a rate of $25-30 \times 10^{9} \mathrm{~kg} / \mathrm{s}$. Few published estimates of the global deep water formation rate exist, and entrainment makes results ambiguous. Ganachaud \& Wunsch (2000) estimated the net vertical return flow across one deep isopycnal as about $30 \times 10^{9} \mathrm{~kg} / \mathrm{s}$.

We imagine a steady state in which a fixed volume flux, $Q$, with a fixed range of temperature and salinity, reaches the sea floor and encroaches on the open ocean. This fluid has little or no net momentum. Convection (Marshall \& Schott 1999) resembles a bulk mixing process in which light and heavy fluid are simply exchanged and/or rendered homogeneous. Many ocean models represent convection by employing very large vertical eddy diffusion coefficients (Marotzke \& Scott 1999). In this situation, the newly dense fluid produces a corresponding pressure gradient (Figure 1).

The overall situation closely resembles that of a "filling-box" (Baines et al. 1993, Bloomfield \& Kerr 1999). Continuously producing heavy fluid of potential density, $\sigma_{2} \leq \sigma \leq \sigma_{1}$ would, in the absence of other physics, gradually fill the abyssal ocean with fluid of this density range. Some process must remove dense fluid and convert it into the lighter overlying fluid. In Figure 1, water in the plume 
is prevented from penetrating to the northern boundary and subsequently rising to occupy the entire water column, assuming that the surface $\sigma=1028.10 \mathrm{~kg} / \mathrm{m}^{3}$ demarcates the upper level of the bottom water.

Convective transfer of relatively dense-near-surface water to the bottom of the ocean is a mechanism for decreasing the system potential energy - the center of mass is continually lowered (see Winton 1995). An associated circulation carries a poleward flux of warm, light water that becomes dense in the "meridional overturning circulation," descending in the polar regions, and returning as an upwelling flux. The upwelling flux requires a process capable of working on the fluid to reraise the center of mass.

Figure 1 suggests that a one-dimensional scale analysis might be useful below about $1000 \mathrm{~m}$ (Munk 1966). If temperature, salinity, and density are local functions, $C_{i}(z), i=1,2, \ldots$, of the vertical coordinate alone, and horizontal velocities and mixing are negligible,

$$
w \frac{\partial C_{i}}{\partial z}-\kappa \frac{\partial^{2} C_{i}}{\partial z^{2}}=0,
$$

(the equation of state is not far from linear), and where $w>0$, is an upwelling velocity. (We discuss lateral advection/diffusion terms later.) Equation 2 represents a steady balance between the upward advection of cold (or relatively fresh) water, and the downward diffusion of heat (or salt). Taking $w, \kappa$ to be constant, a solution to Equation 2 is

$$
C_{i}=C_{0} \exp \left(\frac{w z}{\kappa}\right)+D,
$$

where $C_{0}, D$ are constants, with the latter set, arbitrarily, to zero. The ratio $w / \kappa$ can be determined by fitting to the observed profiles of $C_{i}$. Estimated rates of high-latitude bottom water production, $Q$, can be converted into an estimate of $w$ by assuming uniform vertical upwelling everywhere, producing $w \approx 10^{-7} \mathrm{~m} / \mathrm{s}$ for the global mean, with $\kappa \approx 10^{-4} \mathrm{~m}^{2} / \mathrm{s}$. Attempts to use molecular values for the diffusivities, $\kappa=\kappa_{T} \approx 1.4 \times 10^{-7} \mathrm{~m}^{2} / \mathrm{s}$ for temperature $(T)$, and $\kappa=\kappa_{S} \approx$ $1.5 \times 10^{-9} \mathrm{~m}^{2} / \mathrm{s}$ for salinity $(S)$, produce vertical scales, $k / w$, of $1 \mathrm{~m}$ and $10^{-2} \mathrm{~m}$ for $T$ and $S$, respectively.

Thus, in a low $\kappa$ environment, the deep ocean would be essentially unstratified, with a very sharp boundary layer of less than $1 \mathrm{~m}$ near the surface. [Samelson \& Vallis (1997) gave a dynamically more interesting solution, including lateral advection, but with the same qualitative result.] (See also Toggweiler \& Samuels 1998.) $\kappa$ in Equation 3 must thus represent a turbulent process, and is an "eddy coefficient," $K \approx 10^{-4} \mathrm{~m}^{2} / \mathrm{s}$, best interpreted as across-isopycnal—that is, "diapycnal."

\section{Is the 0 cean Circulation Buoyancy-Driven?}

SANDSTRÖM'S THEOREM The ocean moves immense amounts of heat from tropical to polar regions at rates $\left(\approx 2 \times 10^{15} \mathrm{~W}\right)$ comparable to atmospheric transports (Bryden \& Imawaki 2001). Much of the kinematics of this heat 
transfer involves a meridional overturning circulation, bound up with high-latitude oceanic convection. Because the example of the atmosphere is so familiar, many suppose that the sinking of deep water and subsequent return flow is forced by the high-latitude cooling/evaporation and low-latitude heating/precipitation. Is such a system possible?

The earliest discussion known to us is that of Sandström $(1908,1916)$. He considered the motion induced in a fluid by vertically (and horizontally) separated equal sources of heat and cooling and analyzed the situation in terms of a perfect fluid undergoing a Carnot cycle (Defant 1961, pp. 489-92) (Figure 3). Three cases exist: heating at higher pressure than cooling, heating at lower pressure than cooling, and heating at the same pressure level. We call these convective flows of types 1, 2, 3, respectively. [Stern (1975) terms types 2 and 3 "horizontal convection."] Type 1, apart from the lateral displacement of the heating and cooling sources, is the unstable configuration of Rayleigh-Bénard convection, and work can be extracted from the fluid motion. In type 2, no useful work is produced because expansion takes place at a lower pressure than contraction. Sandström
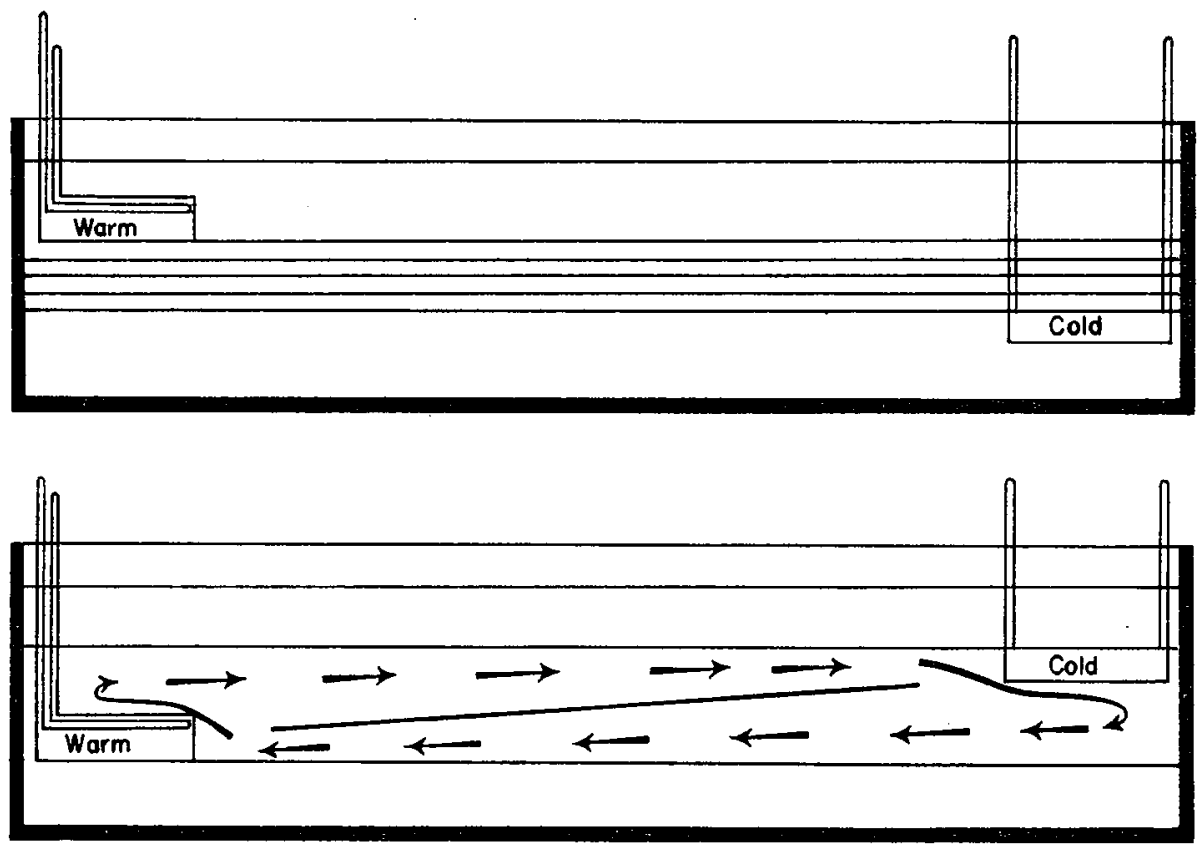

Figure 3 Configurations of the type 1 (lower) and type 3 (upper) convective systems (adopted from Defant 1961) illustrating the arguments of Sandström's theorem. Type 1 convection gives rise to fluid instabilities analogous to those in the Rayleigh-Bénard case. Type 3 fluids are stable, with the cold source fluid filling the abyss of the container, with a weak circulation induced above the cold source by the lateral thermal gradients. 
argued that the fluid below the cold source would become homogeneous at the cold temperature, and that the fluid between the cold and warm sources would be stably stratified with only a creeping, diffusion-limited flow (as Figure 3 shows). In type 3 convection, only a very weak horizontal circulation would be set up in the upper layers of the fluid. Types 2 and 3 are related to the filling box problem.

In the time average, the ocean is heated at low latitudes, where the fluid expands, and is cooled at high latitudes, where it contracts. It appears that the ocean undergoes type 2 convection. Because solar radiation in the tropics penetrates to no more than about $100+\mathrm{m}$, and the longwave cooling principally occurs at the sea surface, some heating occurs at higher pressures than does the cooling. By Sandström's argument, whatever circulation is set up by buoyancy forcing alone would be confined primarily to the region between that of solar penetration and the sea surface; there would be no abyssal flow.

Jeffreys (1925) pointed out that in a real fluid as opposed to the perfect one Sandström had discussed, there must be some motion, and he provided a roughscale analysis of its magnitude. However, he concluded by writing,

The proposition [Sandström's Theorem] may however, be of importance in the movements of the ocean, where radiation, and especially dark heat radiation, can penetrate for much shorter distances than in the atmosphere, and turbulence is practically confined to the neighborhood of the surface. In many oceanic movements conduction may be the chief mode of transfer of heat from one element of water to another, and in such cases the analogy with Sandström's experiment will be very fruitful.

One sometimes hears assertions that Sandström's theorem is irrelevant to the oceanic case. The basis for this claim is simply that the observed oceanic structure is unlike what Sandström described. What the theorem says therefore, is that the observed structure and associated flow are not the result of direct buoyancy driving.

Huang (1999) recently analyzed the motion in a closed tube in the vertical plane subject to heating and cooling at varying levels, confirming the elements of the theorem. Type 3 convection was studied by Rossby (1965), who heated and cooled a laboratory-scale fluid at the same level (the bottom), and later (Rossby 1998) analyzed the experiment numerically. A flow field results from heating and cooling at the same level, but it has a very weak dependence on lateral Rayleigh number. At high Rayleigh number $\left(10^{8}\right)$, the fluid interior is almost isothermal. It is conceivable, but unproven (Paparella \& Young 2002), that at yet higher Rayleigh numbers the system could become unsteady, perhaps resulting in a rectified mean flow.

Paparella \& Young (2002) reformulated the discussion to show that a flow driven by buoyancy forces acting alone at the sea surface cannot generate an interior turbulence. Although their definition of "turbulence" is technical, the result supports Sandström's conclusion. In the absence of interior turbulence, the fluid reaching the seafloor is incapable of generating the mixing necessary for it to 
return to the sea surface across the deep stable stratification. Without a mechanical driving process, the "box" would fill.

\section{MAGNITUDE OF THE MIXING}

How much mixing is observed?

\section{Curve Fitting}

Munk (1966) used the one-dimensional balance in Equation 2 to determine the scale height $K / w$ (using the notation $\kappa=K$ for the turbulent values) by profile fitting, and by introducing observations of oceanic carbon-14, $C_{2}$, he was able to separately determine $w, K . K$ was indistinguishable from the memorable $1 \mathrm{~cm}^{2} / \mathrm{s}$ $\left(=10^{-4} \mathrm{~m}^{2} / \mathrm{s}\right)$, and $w$ was roughly consistent with a uniform return flow of the bottom water flux, $Q \approx 25 \times 10^{9} \mathrm{~kg} / \mathrm{s}$.

In the following years it became clear that $K$ is spatially highly variable, so Munk \& Wunsch (1998) calculated spatial averages of density over entire ocean basins, assuming a value for $w$. The final result was not significantly different from the much simpler 1966 calculation, with an average $K$ below about $1000 \mathrm{~m}$ again of about $10^{-4} \mathrm{~m}^{2} / \mathrm{s}$. However, they found significant vertical variations in $K$, and the equation used in practice was equivalent to,

$$
\bar{w} \frac{\overline{\partial C_{i}}}{\partial z}-\frac{\overline{d K(z)}}{d z} \frac{\overline{\partial C_{i}}}{\partial z}-\overline{K(z)} \frac{\overline{\partial^{2} C_{i}}}{\partial z^{2}}=0,
$$

where the derivative of $K(z)$ behaves analogously to an advective velocity, and is not negligible. (The overbar here denotes a horizontal average over a broad region. This procedure works reasonably well in the ocean interior because the isopycnals are dominantly horizontal far from topography.)

Mixing produces finite distortions in the lateral spatial structure of interior geostrophic flows. By fitting surfaces to the observed density field in the North Atlantic, Olbers et al. (1985) inferred diffusion coefficients in the interior North Atlantic between $800 \mathrm{~m}$ and $2000 \mathrm{~m}$ of about $10^{-5} \mathrm{~m}^{2} / \mathrm{s}$. The Southern Ocean, between $100 \mathrm{~m}$ and $2500 \mathrm{~m}$ generally produced values straddling $K \approx 10^{-4} \mathrm{~m}^{2} / \mathrm{s}$, but with some regions of much larger values $\left(10^{-3} \mathrm{~m}^{2} / \mathrm{s}\right.$ ) at depth. (Climatologies, which involve Reynolds like averaging of the equations of motion, can produce artificial mixing values, depending on the averaging scale.)

\section{Other Direct Estimates}

Hogg et al. (1982) made a direct estimate of mixing from bulk fluid properties in the Vema Channel: Dense fluid enters the Brazil Basin through a narrow passage where its volume flux was determined. No fluid of this density can leave and Hogg et al. (1982) concluded that the heavy fluid had to be mixing vertically at a rate equivalent to $K=(3-4) \times 10^{-4} \mathrm{~m}^{2} / \mathrm{s}$. With the same method, Heywood et al. 
TABLE 1 Spatial-average across-isopycnal diffusviities, as estimated by various budget methods. In the first six rows, the bottom region lies between neutral surface 28.1 and the sea floor (see Figure 1), and from 27.96 to 28.07 for the deep layers. Generally, these lie between about $3800 \mathrm{~m}$ and the sea floor, and between about $2000 \mathrm{~m}$ and $3800 \mathrm{~m}$, respectively, but with considerable spatial variations. The last six estimates are from restricted basins or channels, but all values are spatial averages over the interior and boundary layers

\begin{tabular}{lcl}
\hline Ocean/Depth & $\langle\boldsymbol{K}\rangle\left(\mathbf{1 0}^{\mathbf{- 4}} \mathbf{~} / \mathbf{s}\right)$ & Reference \\
\hline Atlantic, bottom & $9 \pm 4$ & Ganachaud \& Wunsch (2000) \\
Indian, bottom & $12 \pm 7$ &, \\
Pacific, bottom & $9 \pm 2$ &, \\
Atlantic, deep & $3 \pm 1.5$ &, \\
Indian, deep & $4 \pm 2$ &, \\
Pacific, deep & $4 \pm 1$ &, \\
Scotia Sea & $30 \pm 10$ & Heywood et al. (2002) \\
Brazil Basin & $3-4$ & Hogg et al. (1982) \\
Samoan Passage & 500 & Roemmich et al. (1996) \\
Amirante Trench & $10.6 \pm 2.7$ & Barton \& Hill (1989) \\
Discovery Gap & $1.5-4$ & Saunders (1987) \\
Romanche Fracture Zone & 100 & Ferron et al. (1998) \\
\hline
\end{tabular}

(2002) found the remarkably high value of $(30 \pm 10) \times 10^{-4} \mathrm{~m}^{2} / \mathrm{s}$ in the Scotia Sea. These and other estimates are listed in Table 1.

Ganachaud \& Wunsch (2000) described estimates of mixing inferred through very large-scale (ocean basin-scale and larger) budgets of flows into and out of boxes bounded by isopycnals, continental coastlines, and observed temperature, salinity, oxygen, silica, and other sections transecting the ocean basins. Their inferred values are also displayed in Table 1. The main import here is twofold: the deep large-scale geostrophically balanced flow field demands finite abyssal mixing; the rates are similar to those inferred in small volumes such as the Brazil Basin, and from the gross behavior of the density profiles. However, these calculations give integrated, basin-average mixing, and do not distinguish interior values from processes occurring at the boundaries.

\section{Mixing of the Upper Ocean}

MICROSTRUCTURE MEASUREMENTS CoX and collaborators pointed out that turbulent-scale mixing itself must ultimately dissipate on the molecular scale, and that this final dissipation could involve only the molecular coefficients, $\kappa_{T}, \kappa_{S}$, separately for temperature and salt. They developed temperature, and then velocity, profiling devices with sensitive high-speed thermistors and thin films permitting 
direct measurements down to subcentimeter scales. Osborn \& Cox (1972) argued that

$$
3 \kappa_{T} \overline{\left(\frac{\partial T^{\prime}}{\partial z}\right)^{2}}=K\left(\frac{\partial \bar{T}}{\partial z}\right)^{2}
$$

where the overbar now denotes a vertical spatial average over tens of meters, and the prime signifies the departure from the spatial average. Equation 5 permits inference of $K$ from measurements of $T$. Enough "microstructure," $\left(\partial T^{\prime} / \partial z\right)^{2}$, has to exist to permit the molecular diffusion to absorb and dissipate the turbulent eddies stirring the larger scales. Equation 5 assumes that temperature fluctuations are isotropic at molecular scales, so that the temperature dissipation, $\chi$, can be expressed in terms of vertical gradients only,

$$
\frac{\chi}{2}=3 \kappa \overline{\left(\frac{\partial T^{\prime}}{\partial z}\right)^{2}}
$$

Osborn (1980) reformulated the problem so as to permit use of direct measurements of viscous dissipation, $\varepsilon$, from velocity measuring devices where

$$
\varepsilon=\frac{\mu}{\rho}\left[\left(\frac{\partial \mathbf{u}}{\partial x}\right) \cdot\left(\frac{\partial \mathbf{u}}{\partial x}\right)+\left(\frac{\partial \mathbf{u}}{\partial y}\right) \cdot\left(\frac{\partial \mathbf{u}}{\partial y}\right)+\left(\frac{\partial \mathbf{u}}{\partial z}\right) \cdot\left(\frac{\partial \mathbf{u}}{\partial z}\right)\right],
$$

$\rho$ is density, $\mu$ is the molecular dynamic viscosity, and compressive effects have been omitted. He argued that, in a stably stratified ocean, turbulent kinetic energy is produced by the large-scale shear (usually attributed to internal waves) in a stably stratified ocean. Most of this turbulent kinetic energy is dissipated by viscous friction, but a fraction, $\Gamma$, is used to vertically mix the fluid density and raise the center of mass. The relationship between the turbulent diffusivity for density, $K$, and viscous dissipation, $\varepsilon$, is

$$
\varepsilon_{p}=\Gamma \varepsilon=K N^{2} \mathrm{~W} / \mathrm{kg}
$$

where $\varepsilon_{p}$ is the fraction of the dissipation available to actually mix the fluid, and $\Gamma$ is the so-called mixing efficiency commonly thought to be about 0.2. In Equation 8, the diffusivity is that for density, not temperature, a distinction we do not maintain. As reviewed for example, by Gregg (1987), the results generally failed to produce open ocean values of $K$ in the upper $1000 \mathrm{~m}$, below the mixed layer, exceeding about $10^{-5} \mathrm{~m}^{2} / \mathrm{s}$, or about one tenth of the canonical value.

Davis (1994a,b) performed a detailed analysis of the assumptions leading to Equation 5; see Gregg (1998) for a clear summary discussion. Winters \& D'Asaro (1996) gave a different form of rationalization and justification. In both theory and observation (below), there is considerable supporting evidence for the basic ideas. Thus, the inference that the ocean interior above about $1000 \mathrm{~m}$ has values of $K$ significantly less than the values required by macroscopic observations, which respond to intense boundary mixing, remains robust. [The near-surface equatorial ocean is exceptional in this regard; see Gregg (1987).] 
DIRECT MIXING MEASUREMENTS: PURPOSEFUL TRACER RELEASES Lingering doubts about the representativeness of the values of $K$, and of the underlying theoretical assumptions, prompted efforts to obtain more direct measurements of the mixing. These came to fruition in purposeful tracer release experiments (Ledwell et al. $1998,2000)$ in which an inert dye was inserted in controlled fashion into the ocean at depth, and the subsequent evolution was tracked. In summary, the microstructure measurements were vindicated: $K \lesssim O\left(10^{-5} \mathrm{~m}^{2} / \mathrm{s}\right)$ in the open ocean, or one tenth the value believed necessary to support the observed circulation.

Some attempts were made to use dyes to understand mixing at boundaries, primarily in the more manageable setting of lakes. Ledwell \& Hickey (1995) confirmed that in the Santa Monica Basin in California, dye encountering the sidewalls mixed more efficiently there than in the interior. All extant results show that mixing is enhanced over sloping, particularly three-dimensional, topography (Wuest \& Lorke 2003).

\section{Abyssal Mixing}

MICROSTRUCTURE MEASUREMENTS By the 1990s, high-accuracy measurements of $\chi, \varepsilon$ to the sea floor were possible. With confidence obtained from the tracer measurements, Toole et al. (1994), Polzin et al. (1997), Ledwell et al. (2000), and others obtained a series of exciting data. (a) Values of $K \lesssim O\left(10^{-5} \mathrm{~m}^{2} / \mathrm{s}\right)$ persist all the way to the sea floor over abyssal plains and other simple structures (Toole et al. 1994, Polzin et al. 1997). This result conflicts with suggestions (Gargett \& Holloway 1984, Gargett 1989) that $K$ should have simple dependencies on $N(z)$. (b) Greatly enhanced values of $K$ occur over the mid-ocean ridges, generally increasing with depth (Ledwell et al. 2000); over continental slopes with threedimensional structures (K. Polzin, personal communication, 2002); and in some abyssal passages (e.g., the Vema and Samoan Passages and the Romanche Fracture Zone).

These results suggest a picture of weak mixing over most of the ocean volume, from just beneath the upper mixed layer all the way to the sea floor, with $K \lesssim O\left(10^{-5} \mathrm{~m}^{2} / \mathrm{s}\right)$, and with values up to two orders of magnitude higher over rough terrain possessing strong three dimensional structures. However, the vertical extent of enhanced diffusion is unclear. "Smooth" two-dimensional slopes, such as occur sometimes along continental margins, are possibly much less effective than the weakly corrugated structures occurring elsewhere, or the extremely complex three-dimensional terrain of the mid-ocean ridges. Too few measurements are available to attempt a straightforward spatial average anywhere (the distribution is highly non-Gaussian). But when combined with the volume average values of Table 1, and the experiments with dye tracers encountering boundary walls, there is general support for volume average values $\gtrsim 10^{-4} \mathrm{~m}^{2} / \mathrm{s}$ at depth, dominated by an intense boundary process rather than the more familiar (in models, at least) spatially uniform value. However, global average profiles with depth are unknown. 
LARGE-SCALE ABYSSAL FLOW FIELD Localization of abyssal mixing to the boundaries has a radical implication for the gross behavior of circulation dynamics. Geostrophic, hydrostatic balance in the ocean interior leads to the geostrophic vorticity equation (e.g., Pedlosky 1996),

$$
\beta v=f \frac{\partial w}{\partial z},
$$

where $\beta$ is the meridional derivative of the Coriolis frequency $f$, and $v$ is the meridional, geostrophic velocity. Here, $w$ is strictly vertical. Equation 9 means that there can be no meridional flow in the ocean interior in the absence of a vertical velocity $w$. However, if $w$ must cross the nearly horizontal isopycnals, then balances such as Equation 2 imply that significant mixing is required to sustain $w$, and hence the meridional velocity.

Meridional slopes of isopycnals permit finite $w$ over long meridional distances without mixing; Equation 9 implies that these slopes need to be of the order of $w / v \approx(d / a)$, where $a$ is the radius of the earth, and $d$ is the vertical distance over which $w$ has a finite divergence. If $d=1000 \mathrm{~m}, d / a \approx 0.2 \times 10^{-3}$, corresponding to a $200-\mathrm{m}$ isopycnal depth change in a $1000-\mathrm{km}$ north-south displacement. In Figure 1, such slopes are not present over much of the section, but elsewhere (e.g., in the deep water tongue) there are significant slopes. Examining many other such sections shows that any kind of uniform interior meridional transport of any significance is ruled out. Classical textbook pictures such as the abyssal circulation scheme of Stommel \& Arons (1960), based on the assumption of spatially uniform $w$, and hence uniform mixing are not applicable to the ocean. Without large-scale mean isopycnal slopes, abyssal geostrophic interior motions of the ocean must be nearly zonal, $v \approx 0$, as observation (Davis 1998, Hogg \& Owens, 1999) supports. Net meridional fluxes must, by inference, be confined primarily to the regions of strong mixing - presumably over boundaries and rough features such as the mid-ocean ridges, or highly localized regions of strong meridional isopycnal slopes.

\section{Can All Mixing Take Place at the Surface?}

Iselin (1939) noticed that the temperature-salinity relationships imprinted horizontally in the North Atlantic at the sea surface in March were reflected in the same relationships in the vertical across the main thermocline. Interactions between the ocean and the atmosphere appear to mix fluid properties at the surface; subsequently, the fluid is subducted (a recent terminology) to great depths without significant further modifications. In the intervening years, thermocline models were developed (Welander 1971, Pedlosky 1996) showing that realistic vertical stratifications could be produced in the oceanic interior (upper $1000 \mathrm{~m}$ ), over large depth ranges, without any interior vertical mixing at all, a result seemingly consistent with the low interior observed values of $K$. None of these circulation patterns is closed, however. 
Toggweiler \& Samuels (1998), Webb \& Suginahara (2001), and others explored a recent version of these ideas. The motivation can be understood again from Figure 1 . Between 50 and $60^{\circ} \mathrm{S}$, surfaces of constant density outcrop at the sea surface, where the fluid is acted on by a very strong wind forcing and buoyancy exchange. In this region of intense westerlies, the Ekman flux drives fluid strongly from high to low latitudes, and provides a turbulent energy more than adequate to mix fluid at high rates across the near-surface isopycnals. Such a process must be at work, and although it has not been quantified, appears to be a major source of mixing for the upper ocean. However, below about $1300 \mathrm{~m}$, no outcrops appear in the section. Further south, off the end of the data, outcrops do occur, often under ice, but they correspond to regions of injection of deep water masses, not of mixing. Examining the many new hydrographic sections that are available (http://whpo.ucsd.edu) suggests that isopycnals below a bounding isopycnal in a mid-water column do not generally outcrop anywhere, except where deep waters are injected. Figure 4 shows a schematic of the global meridional circulation.

The upper ocean may be dominated by near-surface mixing - at least in the Southern Ocean and the tropics. But concluding that most oceanic mixing takes place at the surface conflicts with the observed need for large mixing at depth (Table 1). There is a considerable literature devoted to surface mixing, watermass formation, and subduction; see Large \& Nurser's review (2001). These processes are important, but seem primarily related to the structure of the thermocline and above, and not to the vast region of ocean volume below the thermocline, which is our present focus.

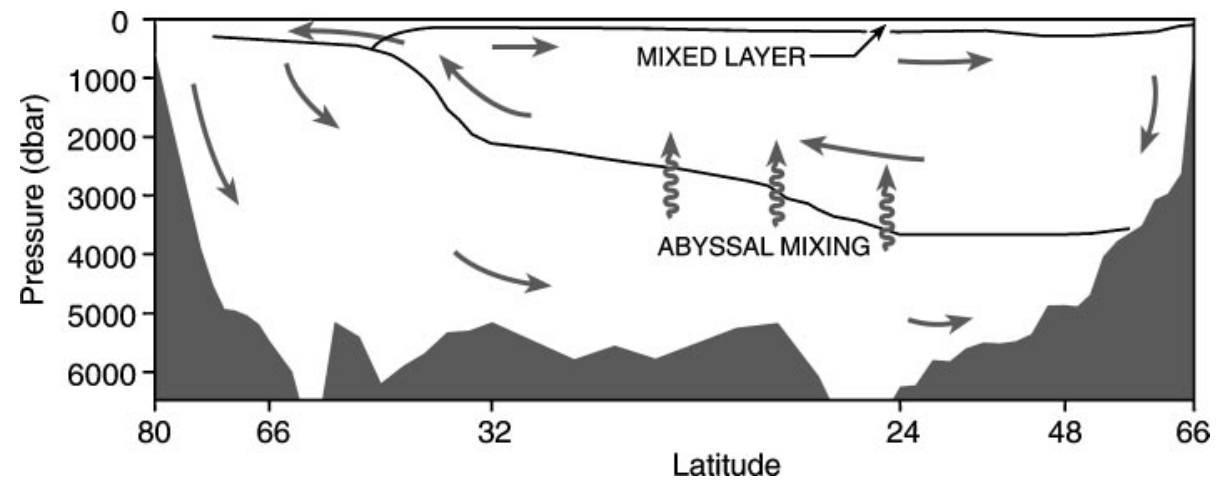

Figure 4 Schematic circulation (adapted from a global calculation of K. Speer, private communication, 2003) showing division into gross meridional circulations in the upper and lower oceans. Relative volumes are approximately correct. Upper volume is strongly mixed in the near-surface regions. Lower one is mixed primarily at the edges and over rough interior topography. There is probably a range of densities at intermediate depths where fluid is mixed both at the sea surface and through abyssal processes in unknown proportions. 


\section{WHAT SUSTAINSTHE MIXING? ENERGY SOURCES}

That the observed ocean circulation requires turbulent mixing to return dense fluid to the upper ocean seems well established. The basic energy balances of a fluid are described in textbooks (e.g., Gill 1982, p. 76). Kinetic energy balance for a fixed fluid element is

$$
\begin{aligned}
\frac{\partial}{\partial t}(\rho E)+\nabla \cdot[(p+\rho E) \mathbf{u}-\mu \nabla E] & =-\rho \mathbf{u} \cdot \nabla \Phi+p \nabla \cdot \mathbf{u}-\rho \varepsilon, \\
E & =\frac{1}{2} \mathbf{u} \cdot \mathbf{u} .
\end{aligned}
$$

$\rho$ is in situ density, $\mu$ is the dynamic viscosity, and $\varepsilon$ was defined in Equation 7. Unlike Gill (1982), the full pressure and density are retained, instead of using perturbations about a rest state. The gravitational potential $\Phi$ includes both the Earth's geopotential, $g z$, and a time-dependent tidal potential $\Phi_{\text {tide }}$, i.e., $\Phi \equiv$ $g z+\Phi_{\text {tide }}(x, y, z, t)$.

Internal energy, $I$, balance per unit mass, is

$$
\frac{\partial(\rho I)}{\partial t}+\nabla \cdot\left[\rho I \mathbf{u}+\mathbf{F}_{r a d}-\rho c_{p} \kappa_{T} \nabla T-\frac{\partial h_{E}}{\partial S} \rho \kappa_{S} \nabla S\right]=-p \nabla \cdot \mathbf{u}+\rho \varepsilon .
$$

$\rho c_{p} \kappa_{T} \nabla T$ in Equation 11 represents the irreversible internal energy fluxes driven by temperature gradients, i.e., the diffusion of heat, with $c_{p}$ the specific heat of sea water at constant pressure. The salinity diffusion term describes the conversion of solution energy into heat, i.e., the generation of internal energy due to the different enthalpies $h_{E}=I+p / \rho$ of pure water and salt. The "compressive work" term $p \nabla \cdot \mathbf{u}$ occurs with an opposite sign in Equations 10 and 11, and is a conversion between internal and kinetic energy. Heat produced by viscous dissipation of kinetic energy, $\rho \varepsilon$, appears as a source of internal energy. $\mathbf{F}_{\text {rad }}$ represents any near-surface radiation to or from the atmosphere.

The rate of change of potential energy per unit mass is

$$
\frac{\partial(\rho \Phi)}{\partial t}+\nabla \cdot(\rho \Phi \mathbf{u})=\rho \mathbf{u} \cdot \nabla \Phi+\rho \frac{\partial \Phi_{\text {tide }}}{\partial t} .
$$

$\rho \mathbf{u} \cdot \nabla \Phi$ also appears in Equation 10, but with an opposite sign; it is the primary path by which potential and kinetic energy are exchanged. The last term is the tidal forcing.

\section{Budgets for the Global Ocean}

The volume integral of the energy conservation laws (Equations 10 through 12), using Stokes's theorem, gives the global ocean energy budgets 


$$
\begin{aligned}
\frac{\partial}{\partial t} \iiint \rho E \mathrm{~d} V= & -\iint \rho E\left(\mathbf{u}-\mathbf{u}_{s}\right) \cdot \hat{\mathbf{n}} \mathrm{d} A-\underbrace{\iint[p \mathbf{u}+\mu \nabla E] \cdot \hat{\mathbf{n}} \mathrm{d} A}_{\text {surface momentum forcing }} \\
& -\mathcal{P}+\mathcal{C}-\mathcal{D} \\
\frac{\partial}{\partial t} \iiint \rho \Phi \mathrm{d} V= & -\iint \rho \Phi\left(\mathbf{u}-\mathbf{u}_{s}\right) \cdot \hat{\mathbf{n}} \mathrm{d} A+\underbrace{\iiint \rho \frac{\partial \Phi_{\text {tide }}}{\partial t} \mathrm{~d} V}_{\text {tidal forcing }}+\mathcal{P} \\
\frac{\partial}{\partial t} \iiint \rho I \mathrm{~d} V= & -\iint \rho I\left(\mathbf{u}-\mathbf{u}_{s}\right) \cdot \hat{\mathbf{n}} \mathrm{d} A \\
& -\iint[\mathbf{F}_{\text {rad }}-\rho c_{p} \kappa_{T} \nabla T-\underbrace{\left.\frac{\partial h_{E}}{\partial S} \rho \kappa_{S} \nabla S\right] \cdot \hat{\mathbf{n}} \mathrm{d} A}_{\text {geothermal and buoyancy forcing }}-\mathcal{C}+\mathcal{D},
\end{aligned}
$$

where $\mathbf{u}_{s}$ is the free-surface velocity. The terms $\mathcal{P}, \mathcal{C}$, and $\mathcal{D}$ are the volume integrals of the conversion terms between the three forms of energy, and describe energy transformations, not energy sources:

$$
\mathcal{P}=\iiint \rho \mathbf{u} \cdot \nabla \Phi d V, \quad \mathcal{C}=\iiint p \nabla \cdot \mathbf{u} d V, \quad \mathcal{D}=\iiint \rho \varepsilon d V .
$$

The first terms on the right-hand side of the three above equations represent the advection of various forms of energy through the surface (advection through lateral and bottom boundaries is excluded by the no-normal flow boundary condition). In steady state, $\iint\left(\mathbf{u}-\mathbf{u}_{s}\right) \cdot \hat{\mathbf{n}} \mathrm{d} A=0$, and these terms must involve a correlation between $E, \Phi$, and $I$ of fluid entering or leaving the ocean and its sense of flow (in or out). Faller (1968) concluded that evaporation and precipitation terms are negligible. Most of this energy is expended in small-scale turbulence near the ocean surface and does not penetrate into the ocean interior.

Surface momentum forcing is composed of the work done by differential pressure and viscous stresses acting on the moving free surface. Pressure work is due to nonhydrostatic effects; work done by the hydrostatic pressure is cancelled exactly by the conversion terms $-\mathcal{P}+\mathcal{C}$ (Ferrari \& Adcroft 2003).

Tidal forcing is very special: It is the only volume source of total energy, $\rho(E+\Phi+I)$. Integration in the vertical is straightforward because the tidal potential has a very weak vertical dependence, and fractional changes of density in the ocean are less than $3 \%$. To a good approximation, tidal forcing is given by the area integral of $\rho \eta \partial \Phi_{\text {tide }} / \partial t$, where $\eta$ is the ocean free-surface elevation. If the actual tides were in equilibrium with the tide-generating force, this term would vanish. Dissipative and dynamical mechanisms generate a global average 
phase difference between the free surface and the tidal potential, so that energy is transferred from the Earth-Moon-Sun system to the oceans (Munk 1997).

Sources of internal energy include heat and salt fluxes through the surface and the boundaries. Energy conversions from salinity changes in the internal energy equation are negligible. In summary, one can identify only a small number of forces acting on the ocean capable of generating an energy supply to the fluid. They are $(a)$ wind, $(b)$ heating and cooling by the atmosphere, $(c)$ exchange of fresh water with the atmosphere, $(d)$ geothermal heating through the sea floor, $(e)$ tides, and $(f)$ atmospheric pressure loading. We examine each possibility in turn in the next section.

\section{Budgets for the Abyssal 0 cean}

The energy budget of the global ocean is dominated by sources and sinks at the boundaries. However, most of this energy does not penetrate far into the ocean interior. Kinetic energy generated by falling precipitation is a good example. It is thus useful to consider energy budgets for interior subvolumes, and follow the fraction of energy that penetrates in those subvolumes. In particular, we are interested in identifying the sources of mechanical energy that drive the abyssal mixing.

Consider the production of kinetic energy for a volume below the ocean surface, confined laterally by the side boundaries, and in the vertical by two level surfaces $\left(z_{1}, z_{2}\right)$. Taking a long time average (denoted by the overbar) in a steady state,

$$
\iint \mathrm{d} A[\overline{\rho E w+p w}]_{z_{1}}^{z_{2}}=-\iiint \mathrm{d} V \overline{\rho g w-p \nabla \cdot \mathbf{u}+\rho \mathbf{u} \cdot \nabla \Phi_{\text {tide }}+\rho \varepsilon} .
$$

Normal flows into solid boundaries and viscous stresses at the lateral boundaries, $\mu \hat{\mathbf{n}} \cdot \nabla E$, are assumed negligible. As a result of averaging between level surfaces, the conversion between kinetic and gravitational potential energies vanishes identically because in a steady state there is no vertical mass flux across any horizontal surface, i.e.,

$$
\iiint \mathrm{d} V \overline{\rho g w}=0 .
$$

The compressive work term can be estimated by making use of the equation of continuity in the form

$$
p \nabla \cdot \mathbf{u}=-\frac{p}{\rho} \frac{D \rho}{D t},
$$

where $D / D t$ is the material derivative. Density can be modified only through compression or diffusion of heat and salt in the ocean interior. Thus, compressive work can be safely neglected in the abyss, because turbulent diffusive fluxes are weak and compressibility effects are small (McDougall 1987). Only close to 
the sea surface do sources and sinks of heat and salt from the atmosphere produce large density variations and generate non-negligible compressive work, $p \nabla \cdot \mathbf{u}$.

Therefore, on the global average, in any volume of fluid below the sea surface, the net dissipation of energy is supplied through the divergence of the pressure work across the upper and lower boundaries, by vertical advection of kinetic energy, and from conversion of tidal potential energy. Contributions to the vertical component of the pressure work terms can come from wave motions, internal and quasigeostrophic. The latter motions (Rossby waves and eddies) are dominated by vertical standing modes whose vertical flux divergences vanish, leaving internal waves as the main candidate. Vertical advection of horizontal kinetic energy across level surfaces is probably (although not easily demonstrated) negligible, involving triple products of the flow field. The dominant balance in Equation 17 becomes

$$
\iint \mathrm{d} A[\overline{p w}]_{z_{1}}^{z_{2}}+\iiint \mathrm{d} V \overline{\mathbf{u} \cdot \nabla \Phi_{\text {tide }}} \approx \iiint d V \overline{\rho \varepsilon},
$$

for kinetic energy in any interior volume.

In contrast, for volumes that extend to the sea surface, the advection term $[\overline{\rho E w}]_{z_{1}}^{\text {surface }}$ dominates, with $E$ becoming extremely large and spatially very inhomogeneous. Regions of direct penetration of sunlight to depth will produce finite pressure work terms $\overline{p \nabla \cdot \mathbf{u}}$, but they are limited in magnitude by the comparatively modest values of $p$. Lueck \& Reid (1984) discussed the surface input terms in greater detail. Equation 20 states that in any region below that of direct wind generation and solar penetration, one must provide the energy necessary to support finite values of $\overline{\rho \varepsilon}$ - principally by divergences of wave radiation processes $[p w]_{z_{1}}^{z_{2}}$ or through external tidal forcing.

Because the conversion term $\rho g w$ vanishes when averaged on a level surface, there is no net conversion of potential into kinetic energy, apart from the tidal component. Furthermore, because the compressive work $p \nabla \cdot u$ is small in the ocean interior, the net conversion of kinetic into internal energy exists only in the form of viscous dissipation.

To estimate the total kinetic energy dissipated in the ocean we now go back to Equations 18 and 19. The gravitational and compressive work terms tend to partly cancel each other in the ocean: Whatever kinetic energy is used to raise a water parcel $(-g \rho w<0)$ is partly compensated by kinetic energy extracted from the internal energy through the adiabatic expansion $(p \nabla \cdot \mathbf{u}>0)$. By introducing the potential density $\sigma$ (see Footnote 1), the two contributions can be lumped into a single conversion term, $g \sigma w$, which represents the net kinetic energy required to lift a water parcel, once reversible adiabatic effects have been subtracted,

$$
g \sigma w \approx-p \nabla \cdot \mu+g \rho w .
$$

This relation is valid only in the ocean interior, where expansion by diabatic effects is weak. Following common practice, we refer to $g \sigma w$ as the conversion between kinetic and potential energies, even though some of the conversion is to internal energy. 
Suppose that we make a decomposition of mean and turbulent terms, based on temporal averaging over a few hours so that,

$$
(\sigma, w)=(\bar{\sigma}, \bar{w})+\left(\sigma^{\prime}, w^{\prime}\right) .
$$

The conversion term in Equation 21 is decomposed as

$$
-\iiint \mathrm{d} V \overline{g \sigma w}=-\iiint \mathrm{d} V g \bar{\sigma} \bar{w}-\iiint \mathrm{d} V \overline{g \sigma^{\prime} w^{\prime}} .
$$

Because the sum of the gravitational and compressive works in Equation 23 nearly vanishes when integrated on a level surface, the sum in Equation 23 is close to zero, the result of cancellation between two large terms on the right-hand side.

The term $\overline{g \sigma^{\prime} w^{\prime}}$ is negative and represents the energy expended by turbulent motions to mix the ocean interior $\left(\varepsilon_{p}\right)$. Munk \& Wunsch (1998) used the closure in Equation 8 and obtained

$$
\iiint d V \rho \varepsilon_{p} \approx 0.4 \times 10^{12} \mathrm{~W}
$$

or 0.4 Terrawatt (TW) for the global ocean below the mixed layer. ${ }^{2}$ Alternatively, one can estimate $\varepsilon_{p}$ by computing the work necessary to lift the abyssal waters through the stratification; the two estimates produce approximate agreement. ${ }^{3}$

We can now use Equation 8 to convert an estimate of $\varepsilon_{p}$ to one for $\varepsilon$. Munk \& Wunsch (1998) took $\Gamma=0.2$ and estimated that 2 TW of energy is dissipated

${ }^{2}$ Obtaining an intuitive sense of such energy numbers is not so easy. Consider that an adult human consumes energy at about $100 \mathrm{~W}$. Thus, two billion adults have an energy requirement of about $0.1 \mathrm{TW}$.

${ }^{3}$ The energy required to lift the abyssal, dense waters through stratification is,

$$
\iiint \mathrm{d} V\left(\sigma_{0}+\Delta \sigma\right) g w
$$

where $\sigma_{0}$ is the potential density of the waters that sink in high latitudes, and $\Delta \sigma$ is the departure from that reference density in the upwelling branch. Without mixing, the downwelling and upwelling waters would have the same density. Mixing introduces an energy source that modifies the potential density of water parcels as they rise across isopycnals, in the return flow of the large-scale meridional overturning circulation. The energy required for this work is represented by the volume integral of $\Delta \sigma g w$. Letting $\mathbf{u}=\left(0,0, w_{0}\right)$, with $w_{0}$ a uniform upwelling of $10^{-7} \mathrm{~m} / \mathrm{s}$, and $\sigma=\sigma_{0}[1-\alpha(z+5000)]$, the energy involved in lifting fluid across the stratification from about $z=-5000 \mathrm{~m}$ to $-2000 \mathrm{~m}$, is given by

$$
\int_{-5000}^{-2000} \Delta \sigma g w \mathrm{~d} z \approx 3 \times 10^{-3} \mathrm{~W} / \mathrm{m}^{2}
$$

where $\Delta \sigma=\sigma(z)-\sigma_{0}$ and $\alpha=3 \times 10^{-7} \mathrm{~m}^{-1}$. The rate of generation of potential energy for the total ocean is now obtained by multiplying $3 \times 10^{-3} \mathrm{~W} / \mathrm{m}^{2}$ by the area of the ocean, taken as $3.5 \times 10^{14} \mathrm{~m}^{2}$. A crude global value is $1 \mathrm{TW}$. 
by viscous stresses. This dissipation is sustained, in a steady state, by the energy transported by internal waves and by tidal forcing, as shown in Equation 20.

Where does this energy come from? Such a question is not normally askededdy coefficients are placed in the equations of motion, often in the Reynolds analogy to the role of molecular coefficients. Consider a thermally stratified, resting fluid. After a very long time, molecular processes render the temperature uniform. A uniformly mixed fluid has a higher center of mass than does a stably stratified one. To raise the center of mass, work must have been done. In the laminar limit, the energy source for this work lies with the particle kinetic energy at the molecular level, manifested through the diffusion coefficient for heat in the internal energy of the stratified fluid (the $\rho c_{p} \kappa_{T} \nabla T$ and $\rho c_{p} \kappa_{T S} \nabla S$ terms in Equation 11). In a model, if one simply replaces molecular diffusion coefficients with eddy coefficients or an equivalent, one introduces a possibly very large, covert potential energy source.

So far we have considered lateral averages across the whole ocean basins. In contrast, integrals over partial volumes of ocean can show steady-state production of potential, kinetic, and internal energies through the conversion terms. Getting much beyond this bland statement is not so easy. Not only does one have direct conversion terms, but the lateral advection of both kinetic and potential energies across open boundaries will not necessarily be negligible and one requires knowledge of the entire density and flow fields.

\section{Wind Forcing}

THE LARGE-SCALE FORCED FLOW Winds acting on the sea surface produce direct conversion of atmospheric kinetic energy into oceanic kinetic and potential energies. Lueck \& Reid (1984) attempted an overall budget and estimated that the net transfer of kinetic energy from the wind field to the ocean-surface layers was in the range of 7-36 TW. Most of this input (e.g., Stern 1975) is supposed to remain in the surface layer, producing turbulent mixing and generating surface gravity waves, which somehow are dissipated (on beaches?), with only a very small fraction going into the large-scale general circulation.

The Ekman layer sets the oceanic general circulation into motion. How is this accomplished? Gill et al. (1974) considered a two-layer ocean subject to a zonal wind stress, $\tau$. Divergence of the resulting Ekman layer generates a vertical velocity, $w_{E}$, which does work against the hydrostatic pressure field, manifested in a downward-deflected isopycnal, $h(x, y)$. ("Ekman pumping," but Ekman suction in upwelling regions also increases the potential energy.) This result implies that the kinetic energy of the wind (in $w_{E}$ ) is converted at a rate $W_{\tau}^{(1)}$ into oceanic potential energy by the work of $w$ against the ambient pressure field. ${ }^{4}$ However,

\footnotetext{
${ }^{4} \mathrm{~A}$ large literature exists on defining and determining the component of potential energy that is "available" (e.g., Winters et al. 1995), and is a subject of great complexity. Here, no such distinction is necessary, as any portion of the potential energy that is involved in the budget of production or conversion/destruction is, by definition, "available".
} 
associated with the potential energy is a geostrophic flow field

$$
\mathbf{u}_{g}=\frac{1}{\rho f} \hat{\mathbf{k}} \times \nabla p,
$$

with a corresponding kinetic energy. The rate of work done by the wind on the ocean is the force times displacement per unit time, $\tau \cdot \mathbf{u}_{g}$ and which, when spatially and temporally integrated, produces an estimate $W_{\tau}^{(2)}$. One finds, very generally, $W_{\tau}^{(2)}=W_{\tau}^{(1)}$, and thus an equally valid view is that the energy transfer from atmosphere to the ocean is by direct generation of oceanic kinetic energy. In nearly geostrophic systems, all structures have both kinetic and potential energies (their ratio depends on the horizontal scale of the motion), and no uniquely definable energy pathway exists. $\mathbf{u}_{g}$ is the geostrophic velocity component and so $W_{\tau}$ includes no energy input into small-scale motions. Either computation is a measure of the energy input by the wind directly into the oceanic general circulation. Using $\tau \cdot \mathbf{u}_{g}$, Wunsch (1998) found global values $\approx 0.8 \mathrm{TW}$ with about $80 \%$ entering in the Southern Ocean. Gill et al. (1974) suggested that wind energy was exported to western boundary currents and there dissipated, and also that the energy was removed by baroclinic instability. Further discussion of energy sinks is postponed until we consider other possible sources.

INTERnal WAVES AT NONTIDAL PERIODS The ocean is filled with a ubiquitous field of internal waves, generally accurately described by the Garrett \& Munk (1979) spectrum. Müller et al. (1986) and Staquet \& Sommeria (2002) provide useful reviews. The large shear associated with low frequencies, and the possibility of convective instabilities, led to the general view that much, if not all, oceanic mixing occurs through the "breaking" of the internal wave field. There have been a number of serious attempts (Garrett 1979, Munk 1981, Gargett 1989) to quantify the rates at which the internal wave field can mix the ocean. Recent results are the theoretical discussion of Henyey et al. (1986), and the observational review of Gregg (1989).

The picture remains incomplete, but a summary would be that open-ocean mixing rates from internal waves are consistent with the measured values $K \approx O\left(10^{-5} \mathrm{~m}^{2} / \mathrm{s}\right)$. Ambient internal wave-breaking away from topography appears to be capable of explaining the observed background mixing in the open ocean, but not the global average, which is 10 times higher. A major question is whether boundary interactions of internal waves make up the difference.

What are the sources of internal wave energy? Owing to the strong nonlinear interactions, and the apparent long decay time (Garrett 1979), several possibilities exist: (a) direct surface wind generation; $(b)$ indirect internal wave generation through fluctuations of the mixed-layer depth (Townsend 1965); (c) indirect surface generation by nonlinear interaction of surface gravity waves; $(d)$ tidal flows over topography; $(e)$ other flows over topography (mesoscale eddies and the large-scale circulation); and $(f)$ generation in the mesoscale variability through loss of balance. All of the above mechanisms except tidal generation depend on the wind strength. 
The observed internal wave spectrum contains a large peak near the inertial frequency, $f$ (Fu 1981, Garrett 2001), only partially accounted for by the GarrettMunk description. This peak contains much energy and vertical shear. Alford (2003) calculated a wind deposit of energy into this peak at about $0.5 \mathrm{TW}$.

\section{Tidal Input}

The sun and the moon work on the ocean at rates known with near-astronomical accuracy (Munk \& Wunsch 1998). A best-estimate value is a 3.5-TW energy input into the ocean by the tides. Conventionally, tides have been thought to dissipate on the continental shelves where the energy input would be irrelevant to the general circulation. Although it has been known for many years that there are baroclinic motions at the tidal period in the open ocean, it was generally believed that they were not significant.

Unexpectedly, internal waves of tidal period are detectable in satellite altimeter data (e.g., Egbert \& Ray 2000), and also tomographic records (Dushaw et al. 1995); they are ubiquitous and large, and apparently more effective at mixing the ocean than previously thought. Munk \& Wunsch (1998) calculated that of the 3.5 TW of tidal dissipation, as much as $1 \mathrm{TW}$ could be available to mix the abyssal ocean. More recent observations (Egbert \& Ray 2000) support this inference, but 1 TW is likely an upper-bound.

Forced motion of fluid over topographic gradients generates internal waves of tidal period and turbulence in the complex of boundary layers possible in a rotating stratified fluid. Tidal-period internal waves can transmit their energies over long distances, and thus also mix the fluid remotely from the generation region through further encounters with topographic gradients (see Rudnick et al. 2003). Hypothetically, they could also sustain the broadband internal wave field (Müller et al. 1986). To simplify the discussion, we choose to regard the turbulent motions driven by the barotropic tide as a collective forcing of the kinetic energy equation, hiding all of the detail. In contrast to the wind field, tidal forcing is introduced at great depth and is thus efficiently placed for deep mixing.

\section{Geothermal Heating}

Like the wind field, and unlike internal wave mixing, geothermal heating is capable of influencing the general circulation on all space scales including the very largest. Despite the heating from below, fluxes are small and the resulting flows are weak (Scott et al. 2001). Huang (1999) estimated net energy input as 0.05 TW (correcting a factor of 10 in his paper).

\section{Buoyancy Forcing}

Huang \& Wang (2003) calculated the net buoyancy work done on the ocean by exchanges with the atmosphere. Heating the fluid over the mixed-layer depth, $h_{m}$, forces the fluid column to expand, with a net rise in the center of mass and 
an increase in potential energy (positive from the elevation of the sea surface, part-compensated by the mass-reduction at depth; e.g., Winton 1995, Huang \& Wang 2003). Cooling, causing a contraction, lowers the center of mass, and hence the potential energy. Generally speaking, cooling occurs during periods when mixed layers attain considerably greater thickness than occurs during heating, resulting in a more efficient removal of potential energy. A great difficulty with the calculation concerns the role of high frequency, intense storm events, and the strong diurnal cycle. However, all the numbers tend to be small compared to the wind forcing, and currently, the best estimate of the work done by buoyancy forcing on the ocean is zero.

In Rossby's $(1965,1998)$ type 3 laboratory experiment, there is a weak, completely thermally driven flow, but the author did not analyze the energetics. On the laboratory scale of course, $K=\kappa_{T}$, the molecular value, for which the energy source is known.

A few estimates (e.g., Faller 1968, Huang 1998) exist of the potential energy input owing to fresh water exchange (evaporation and precipitation) between ocean and atmosphere. All of these estimates produce very small negative numbers (Huang's value is $-0.01 \mathrm{TW}$ globally), but the value is uncertain. On average, the warm tropics with high-standing sea level are regions of evaporation; precipitation tends to occur in high latitudes of low sea level, both therefore tending to reduce the potential energy. For present purposes at the level of accuracy with which one can make budgets, these contributions are also estimated as zero.

\section{Atmospheric Pressure Loading}

In principle, fluctuations in nontidal atmospheric pressure loading can do work on the ocean circulation (e.g., Ponte 1994, Wunsch \& Stammer 1997). R. Ponte (personal communication, 2002) estimated the total nontidal pressure-loading work at about $10^{-2} \mathrm{TW}$.

\section{Summary of Energy Inputs}

Figure 5 displays a crude summary diagram of energy inputs and dissipation rates in a steady-state ocean. Many of the values shown are targets slated for replacement, and some numbers have been omitted altogether. A few inferences appear robust, such as: (a) The ocean circulation is not a heat engine. Buoyancy exchanges between ocean and atmosphere, far from forcing a measurable large-scale circulation, are weak and may even be net sinks of oceanic potential energy. (b) Both the large-scale meridional overturning mass circulation and baroclinic instability of the circulation as a whole release potential energy in roughly equal amounts, totalling very approximately $2-3 \mathrm{TW}$. Some (small) additional energy would be required to compensate the mechanical energy losses in lateral- and bottom-frictional boundary layers. $(c)$ The resupply of potential energy, necessary to maintain the observed stratification below the directly wind-blown, turbulent layers, must therefore come from the conversion of kinetic energy. Only two important sources of 


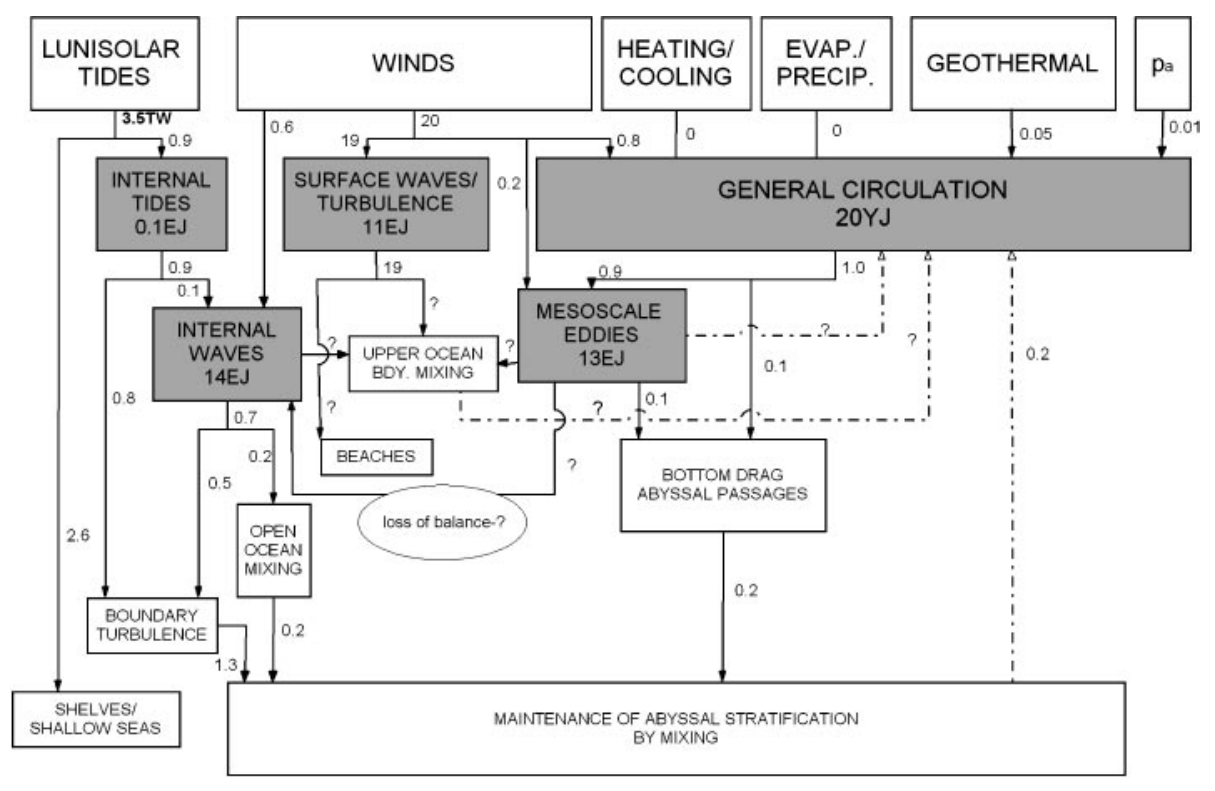

Figure 5 Strawman energy budget for the global ocean circulation, with uncertainties of at least factors of 2 and possibly as large as 10. Top row of boxes represent possible energy sources. Shaded boxes are the principal energy reservoirs in the ocean, with crude energy values given [in exajoules (EJ) $10^{18} \mathrm{~J}$, and yottajoules (YJ) $10^{24} \mathrm{~J}$ ]. Fluxes to and from the reservoirs are in terrawatts (TWs). Tidal input (see Munk \& Wunsch 1998) of 3.5 TW is the only accurate number here. Total wind work is in the middle of the range estimated by Lueck \& Reid (1984); net wind work on the general circulation is from Wunsch (1998). Heating/cooling/evaporation/precipitation values are all taken from Huang \& Wang (2003). Value for surface waves and turbulence is for surface waves alone, as estimated by Lefevre \& Cotton (2001). The internal wave energy estimate is by Munk (1981); the internal tide energy estimate is from Kantha \& Tierney (1997); the Wunsch (1975) estimate is four times larger. Oort et al. (1994) estimated the energy of the general circulation. Energy of the mesoscale is from the Zang \& Wunsch (2001) spectrum (X. Zang, personal communication, 2002). Ellipse indicates the conceivable importance of a loss of balance in the geostrophic mesoscale, resulting in internal waves and mixing, but of unknown importance. Dashed-dot lines indicate energy returned to the general circulation by mixing, and are first multiplied by $\Gamma$. Open-ocean mixing by internal waves includes the upper ocean.

such kinetic energy exist, the wind stress and tidal flows. The tides can account for approximately $1 \mathrm{TW}$, at most. The wind field provides approximately $1 \mathrm{TW}-$ directly - to the large-scale circulation and probably at least another 0.5 TW by generating inertial waves and the internal wave continuum.

Taken together, Sandström's (1908, 1916) and Paparella \& Young's (2002) theorems, the very small, probably negative, contribution to oceanic potential energy by buoyancy exchanges with the atmosphere, and the ready availability of 
kinetic energy provided by winds and tides, one perceives the ocean circulation as a mechanically controlled system, but capable of moving immense amounts of heat, fresh water, and other properties.

\section{RATES OF DISSIPATION - THE GLOBAL SCALE}

How is the general circulation of the ocean dissipated? Three candidates exist. (a) The first is baroclinic and barotropic instabilities of the circulation through the generation of mesoscale eddies and related phenomena. However, this mechanism represents a path toward dissipation, not dissipation itself. (b) The second candidate is drag forces on the sea floor (turbulent boundary layers); drag on topographic features of all scales; mechanical interaction with the sloping sidewalls, both from the mean circulation and from the eddy field. (c) The third is energy conversion from the large-scale balanced flows into internal gravity waves and small-scale turbulence, the latter to be eventually dissipated.

\section{Instability and the Mesoscale}

Oceanic kinetic energy is dominated by approximately a factor of 150 (e.g., Wunsch 2002a, Figure 2) by time-dependent elements, which are in turn spatially dominated by scales of the order of $200 \mathrm{~km}$ relative to the time-average flow. About $60 \%-70 \%$ of that energy is baroclinic (e.g., Wunsch 1997).

Although there can be direct generation of variability by the wind field (e.g., Frankignoul \& Müller 1979, Stammer et al. 2001), most of the baroclinic energy is the result of instabilities in many forms (Pedlosky 1987). The importance of eddies in the ocean circulation varies from slight over most of the open ocean, to very important in western boundary regions, and in the Southern Ocean (e.g., Karsten et al. 2002). This vast reservoir of kinetic energy contributes little to oceanic vertical mixing because baroclinic instability results in the extraction of potential (and kinetic) energy from the large-scale circulation (Pedlosky 1987); it cannot increase the potential energy, which is the requirement for a vertical mixing process. Dissipation of the eddies over topography or elsewhere and/or loss of geostrophic balance could produce mixing. "Stirring" by the mesoscale, the stretching out of scalar properties through advection in a reversible process, is important to the ultimate efficacy of mixing, as in Taylor dispersion. But it does not produce the irreversible process essential to the potential energy increase, unless the related potential vorticity stirring leads to significant failure of the quasi-geostrophic balance.

Because baroclinic instability removes potential energy from the system, it must be replenished by the same external forcing candidates already listed. To estimate the conversion rate of potential energy from the large- to the mesoscale, we separate the conversion term in Equation 23 into three components associated respectively with the mean circulation, mesoscale eddy motions, and turbulent mixing,

$$
-\iiint \mathrm{d} V \overline{g \sigma w}=\mathcal{G}_{\text {mean }}+\mathcal{G}_{\text {eddy }}+\mathcal{G}_{\text {turbulence }} \approx 0 .
$$


(This decomposition makes sense only if there is no upgradient flux from the eddies to the mean.) Munk \& Wunsch (1998) found the mixing term $\mathcal{G}_{\text {turbulence }}$ to be of the order of $-0.4 \mathrm{TW}$ (that is, production of potential energy). The other two terms represent the conversion of potential into kinetic energy by restratification and are expected to be positive. The kinetic energy lost at small scales must be cancelled by the low-frequency mean term in Equation 23 if the total integral is to vanish. Sources of large-scale kinetic energy include geostrophic adjustment events, baroclinic instability, and the meridional overturning circulation. In the Munk \& Wunsch (1998) budget, only the meridional overturning circulation was included.

Gent \& McWilliams (1990) proposed a parameterization that relates $\mathcal{G}_{\text {eddy }}$ to the mean density structure of the ocean, $\sigma_{\text {mean }}$ (see the general discussion in Tandon $\&$ Garrett 1996, and the review by Toole \& McDougall 2001). Their parameterization is

$$
\mathcal{G}_{\text {eddy }}=-\iiint \mathrm{d} V K_{G M c} g \frac{\left|\nabla_{H} \sigma_{\text {mean }}\right|^{2}}{\partial \sigma_{\text {mean }} / \partial z}
$$

where $K_{G M c}$ is an empirical parameter, tuned in numerical models to give "reasonable" results for large-scale tracer fields.

Huang \& Wang (2003) estimated the eddy conversion term in Equation 29 from hydrographic climatology, taking $K_{G M c}=1000 \mathrm{~m}^{2} / \mathrm{s}$, as the value appropriate for open-ocean mesoscale eddies. Their rough estimate was 1.3 TW. The largest values of mean conversion by baroclinic eddies appear in the Southern Ocean, the same region where the wind-work energy input estimated by Wunsch (1998) also is a maximum. We repeated the same calculation with two different parameterization schemes, one by Visbek et al. (1997), and the other by Danabasoglu \& McWilliams (1995). Their parameterizations differed in the handling of regions with weak stratification $\partial \sigma_{\text {mean }} / \partial z$, and which dominate Equation 29. Estimates of 0.2 and $0.8 \mathrm{TW}$, respectively, are obtained. The reliability of these numbers is thus difficult to judge because it depends on the empirical coefficient $K_{G M c}$, the particular parametrization scheme, and the underlying density climatology.

Owing to the large uncertainty in the estimate of the eddy conversion term, it is unclear how the balance in Equation 28 is satisfied. What is clear is that a large fraction of the potential energy generated by the winds is lost through baroclinic eddies. The Southern Ocean emerges as a unique region with intense input from the mean winds, and because of the mostly homogeneous physics, a region of large net generation of baroclinic eddies. Some energy of unknown magnitude must be left over to balance the bottom drag terms.

\section{Mesoscale Dissipation Rates}

Little is known about mesoscale eddy dissipation; models can say little, for various reasons. Zang \& Wunsch (2001) estimated the spectrum of mesoscale variability as a function of position; the average value (X. Zang, personal communication, 2002) 
for the mesoscale energy, about 26 exajoules $\left(1 \mathrm{EJ}=10^{18} \mathrm{~J}\right)$, is used in Figure $5 .^{5}$ If it is generated at the rate estimated by Huang \& Wang (2003), it would all have to be dissipated about every six months. Fu et al. (1982) noticed that eddy energy over the very rough topography of the Mid-Atlantic Ridge was depleted below the main thermocline, a result consistent with inferences from altimeter measurements (Gille et al. 2000). No quantitative measure of the rate of dissipation implied is available. Additional energy exists in the barotropic mode and higher baroclinic ones; this energy and any direct wind-input would also lengthen the decay time. This discussion can be carried no further. But the large vertical scale of mesoscale eddy energy in the ocean precludes a direct significant contribution to mixing rates unless loss of near-geostrophic balance is very efficient.

\section{Drag Forces on the General Circulation}

Flows through abyssal passages generate intense mixing (Ferron et al. 1998, Hogg et al. 1982). The energy required to sustain this mixing comes from the large-scale wind work both on the mean and fluctuating circulations, plus whatever the eddy field does in such regions. Assuming that the large mixing rates seen in these passages are due to turbulence induced by the mean or eddy flow, and not by tidal and ambient internal wave mixing (the authors do not report any anomalously large tidal or internal wave signals), then one can obtain a crude estimate of the total dissipation. Taking the Romanche Fracture Zone as an example, Ferron et al. (1998) reported $K \approx 150 \times 10^{-4} \mathrm{~m}^{2} / \mathrm{s}$ over $10^{3} \mathrm{~km}^{2}$. Converting back to $\varepsilon_{p}$, using Equation 8, a value of $N$ corresponding to a five-hour period, and a vertical extent of $500 \mathrm{~m}$ (Ferron et al.'s Figure 2c),

$$
\varepsilon_{p} \approx 1.8 \times 10^{-9} \mathrm{~W} / \mathrm{kg},
$$

and

$$
\iiint \rho \varepsilon d V \approx 4.5 \times 10^{6} \mathrm{~W}
$$

Although the local value is very high, it occupies only a fraction of the water column, and the area of the Fracture Zone is small. Even 1000 Romanche Fracture Zones would generate a negligible contribution to the total. Effects of the fracture zones and channels will likely be small in the overall energetics and abyssal mixing. In Figure 5, 0.1 TW is assigned as the rate of dissipation at the bottom for both the large-scale circulation and the eddy field, as barely significant placeholders. The vast area of the Southern Ocean is a region of potentially unusually strong nearbottom mixing, with its intense input of wind energy, rapid barotropic variations at high frequencies (e.g., Stammer et al. 2000), and strong mean and eddy flows across large ridge systems.

${ }^{5}$ There is an error of 100 in the Wunsch (1998) result. 


\section{Balancing the Budget}

Assuming the mesoscale generation value is about $1 \mathrm{TW}$, this number must be added to that required by the meridional overturning circulation. If the latter is also about 1 TW (see Footnote 3 ) one has a total required energy input into the circulation of about 2 TW. To the degree that eddies are generated directly by the wind, one would subtract that contribution. Frankignoul \& Müller (1979) estimated a wind-driven eddy-generation rate of about $5 \times 10^{10} \mathrm{~W}=0.05 \mathrm{TW}$, which is negligible at the current levels of budget accuracy. We identify corresponding energy sources summing to about 1.7 TW for the abyssal circulation (Figure 5). (One would like to have a global integral value for $\rho \varepsilon$, which could be equated to the energy input, but no useful estimate is available.) Consequently, the total numbers for input and dissipation are somewhat different, but given the great inaccuracies and assumptions involved in their calculation, one is gratified that they come out so close!

The picture that emerges in Figure 5 differs in two major ways from that described by Munk \& Wunsch (1998): ( $a$ ) it accounts for the generation of mesoscale eddies, and $(b)$ the net wind work on the general circulation does not go significantly into the abyssal mixing budget; instead it is lost primarily to baroclinic and other instabilities, with only a minor component available for mixing in the abyssal passages and fracture zones. We postulate that the ambient internal wave accounts for the great bulk of both the combined interior and boundary mixing, be it tidally or wind-forced, or generated by loss of balance in the mesoscale.

\section{BOUNDARY MIXING AND INTERNAL WAVES}

Munk (1966) proposed that ocean boundaries are the primary regions of oceanic mixing, but the possibility attracted little attention at the time. Internal waves were always implicated strongly because of the very high wavenumbers generated when such waves encounter sloping boundaries (Phillips 1977), and internal tides can also be preferentially generated there. Garrett \& St. Laurent (2002) reviewed recent work on the generation problem. More recent additions to the literature include Balmforth et al. (2002), St. Laurent \& Garrett (2002), Llewellyn-Smith \& Young (2002), Legg \& Adcroft (2003), and Khatiwala (2003).

Eriksen (1985) studied three-dimensional wave reflections, and some work has been done on the mean flows generated on two- and three-dimensional reflection (e.g., Thorpe 2001), but this subject warrants its own review. An extreme version of internal waves encountering slopes occurs in the canyon-like features incised into the continental margins and occurring as substructures of the mid-ocean ridges. It has been known for a long time that waves focusing into the canyons can produce energy densities far in excess of those found in the open sea, with consequent greatly enhanced dissipation (Petruncio et al. 1998, St. Laurent et al. 2001, Kunze et al. 2002). Dissipative boundary layers in a rotating stratified fluid can be remarkably intricate (Phillips et al. 1986, Garrett et al. 1993), and the subject is not 
well explored. These layers, and the near-hyperbolic behavior of inviscid waves, render computation of the flow field a serious challenge to any large-scale numerical model.

Real ocean topography is extremely complicated and the resultant mixing from all possible sources has not been parameterized (Jayne \& St. Laurent 2001 suggested a form for the tidal component). What observational evidence does exist suggests that the full three-dimensional structures and slopes of the local topographies will enter any useful parameterization.

\section{MODELS}

Numerical general circulation models are a powerful tool for understanding the ocean. However, in their present state they prove not as helpful in elucidating mixing and energetics as one might anticipate. Several sources of difficulty can be identified, including the arbitrary introduction of eddy-mixing coefficients with numerical values tuned to provide realistic simulations. These lack any link to the underlying sources of the implicit turbulence. That is, they imply a turbulent field, but one without an associated energy source; this omission is of particular concern in models without any wind forcing, including even simple box models [e.g., variants of Stommel (1961)]. Another source of difficulty is the near-ubiquity of the Boussinesq approximation (several versions in several numerical representations), which renders problematic even a gross energy budget for the system. Reasons of space preclude a serious discussion of the energetics and mixing in models, and we regretfully defer this important subject (but see Huang \& Wang 2003).

\section{MIXING EFFICIENCY}

The parameter $\Gamma$ appearing in Equation 8, known as the mixing efficiency, relates the total system dissipation, $\varepsilon$, to the fraction actually available to mix the fluid. It is commonly written in terms of the flux Richardson number $R i_{f}=N^{2} /(d U / d z)^{2}$, where $U$ is a large-scale horizontal flow (see Turner 1973) and

$$
\Gamma=\frac{R i_{f}}{1-R i_{f}} .
$$

A value $\Gamma \approx 0.2$ is often used. Much controversy exists over the expectation that it should be a universal constant. A recent review by Peltier \& Caulfield (2003) provides examples of flows with mixing efficiencies as large as 0.5 . However, recent controversial laboratory experiments on grid turbulence in stratified fluids suggest that $\Gamma$ drops abruptly with increasing $\epsilon / N^{2}$ (Barry et al. 2001). The oceanographic problem has a large literature of its own. If $\Gamma$ was much smaller, on average, than values around 0.2 , it would increase the required supply of external mechanical energy as deduced from the measurements of $\varepsilon$, and increase most of the interior 
energy flux numbers in Figure 5. Currently, it is not possible to say anything useful about spatial and temporal variability of $\Gamma$ in the ocean, but progress may be at hand (Canuto et al. 2001).

\section{SUM MARY AND CONCLUSIONS}

The statistically steady ocean circulation appears to be a mechanically forced phenomenon; despite its transport of enormous amounts of heat energy, it is not buoyancy-driven. Its essential energetics are the conversion of kinetic energy of the wind and tides into oceanic potential and kinetic energy through the generation of the large-scale circulation. Heating/cooling/evaporation/precipitation directly affect the ability of the wind to create potential energy, but they are only slightly involved in the energy cycle, possibly even reducing the potential energy. The energy contained in the large-scale circulation (mainly, but not solely, potential) is converted into kinetic energy in the interior through baroclinic and barotropic instabilities. (Spin-up of the ocean from rest is a completely different process.)

To maintain the stratified steady state, whose potential energy is released by the resulting meridional overturning circulation and generation of the eddy field, a source of kinetic energy is required to mix the dense fluid across the observed stable stratification. Kinetic energy in the large-scale circulation and mesoscale eddies does not have any significant direct role in the required mixing. Much, if not all, of the mixing energy is bound up in the internal wave field, including components of tidal origin. Direct internal wave generation by the wind field at the sea surface is probably a major, if poorly quantified, source; this energy can radiate throughout the ocean. A second major source is the abyssal tidal flow, where the kinetic energy is directly implanted at great depth. A third unquantified source is generation of internal waves through interactions of the mesoscale eddy field with bottom topography, and through conversion by other processes into nonrotationally balanced motions. Internal wave energy can sustain large-scale, but weak, interior mixing through localized instabilities, and produce extremely strong mixing in the presence of complex topographic gradients. A global average vertical profile of mixing of either type is unavailable. An attempt to balance the budgets of energy input into the large-scale circulation against the rate of work required to maintain it succeeds qualitatively. Numerous assumptions and inaccuracies are involved.

In quantifying the relative contributions of winds and tides, it appears that by pushing the limits of physical possibility, tidal mixing can account for approximately half of the required abyssal energy, with the wind providing the remainder. To the degree that the total required energy has been underestimated, perhaps through use of too large of a mixing efficiency $\Gamma$, the wind field produces so much kinetic energy in the near-surface ocean that even if only a modest additional fraction radiates into the interior, it would be adequate to provide the energy. This view contrasts with the picture that places all mixing in the near-surface boundary layers. Such a process is undoubtedly an important contribution to the circulation 
of the upper ocean, but it appears neither necessary nor sufficient to explain the abyssal stratification, which does not display the required surfacing of the deep isopycnals.

It is unclear the degree to which the oceanic meridional overturning circulation and the related transports of heat and chemical properties are rate-limited by particular mechanisms. In the atmosphere, the limit set on the meridional overturning circulation (the Hadley Cell), by an upper bound on the radiative cooling (see Emanuel et al. 1994) would be an analogue of the control of the ocean circulation by available mixing rates. But one can only get so far in a quantitative determination of the oceanic energy balance without an actual knowledge of the full three-dimensional flow field.

Major omissions in the energy conversion discussion here include the effects of double and differential diffusion (see Gargett 1989) and transformations dependent on the nonlinearities of the equation of state (e.g., Fofonoff 1998). Potential energy can be released through these processes, and a full budget will eventually have to account for them, but the ultimate forcing still lies at the sea surface. These processes warrant a full review of their own.

Energy arguments undermine the widespread belief in a "thermohaline" circulation-driven by surface buoyancy forces; the fundamental driver of the circulation is the wind field, including that part which transports heat and fresh water (Wunsch 2002b). Buoyancy exchange at the sea surface partially controls the properties of the circulation, including the heat budget, but the fundamental aspect- the movement of mass - is dominantly wind- and tide-driven.

Questions of oceanic energetics and mixing are perhaps most important in efforts to calculate the ocean state under very different conditions than those existing today. That is, models are tuned to produce realistic-appearing circulations using eddy coefficients and other parameterizations that may compensate for qualitatively or quantitatively incorrect system energetics and other problems. In past climate states, there were radically different configurations of continents, wind systems, mean atmospheric temperatures, locations of large ice sheets, sea level, and the like. Both wind- and tide-induced mixing rates must have shifted greatly. Models carrying covert sources of kinetic and potential energy will be deeply suspect, particularly when run over long periods of time.

Many issues remain. We lack quantitative understanding of several things, including: $(a)$ the energy budget for the upper turbulent layer of the ocean in direct contact with the wind field; $(b)$ the sources controlling the internal wave energy in the ocean and the rate at which it is dissipated; (c) a global estimate of the mechanisms of the dissipation of wind energy including surface waves; (d) parameterizations of the mixing generated by the interaction of internal waves, mesoscale eddies, high-frequency barotropic fluctuations, and other motions over sloping topography, best written as $K(\tau, x, y, z)$, where $\tau$ is the wind stress; $(e)$ the mechanisms dominating the dissipation of mesoscale eddies; and $(f)$ the net effect of bottom drag, particularly as it occurs in narrow passages such as the Vema Channel. All of these are critical to any claim to forecast future climate 
states as they appear to largely control the mass, heat, and freshwater budgets of the oceans.

\section{ACKNOWLED GMENTS}

We had very useful comments and corrections from C. Garrett, E. Kunze, J. Marshall, E.D'Asaro, R.X. Huang, W. Young, and A. Gargett. Remaining errors and obscurities are all ours, however. Partially supported (C.W.) by the National Ocean Partnership Program (NOPP) through funding of ONR, NSF, and NOAA to the ECCO Consortium, and by ONR (R.F.).

\section{The Annual Review of Fluid Mechanics is online at http://fluid.annualreviews.org}

\section{LITERATURE CITED}

Alford MH. 2003. Improved global maps and 54-year history of wind-work on ocean inertial motions. Geophys. Res. Letts. 30(8): art. no. 1424

Baines WD, Corriveau AF, Reedman TJ. 1993. Turbulent fountains in a closed-chamber. $J$. Fluid Mech. 255:621-46

Balmforth NJ, Ierley GR, Young WR. 2002. Tidal conversion by subcritical topography. J. Phys. Oceanogr. 32:2900-14

Barry ME, Ivey GN, Winters KB, Imberger J. 2001. Measurements of diapycnal diffusivities in stratified fluids. J. Fluid Mech. 442:267-91

Barton ED, Hill AE. 1989. Abyssal flow through the Amirante Trench (Western Indian Ocean). Deep-Sea Res. A 36:1121-26

Bloomfield LJ, Kerr RC. 1999. Turbulent fountains in a confined stratified environment. $J$. Fluid Mech. 389:27-54

Bryden HL, Imawaki S. 2001. Ocean heat transport. See Siedler et al. 2001, pp. 455-74

Canuto VM, Howard A, Cheng Y, Dubovikov MS. 2001. One-point closure model. Momentum and heat vertical diffusivities. $J$. Phys. Oceanogr. 31:1413-26

Davis RE. 1994a. Diapycnal mixing in the ocean: equations for large-scale budgets. $J$. Phys. Oceanogr. 24:777-800

Davis RE. 1994b. Diapycnal mixing in the ocean: The Osborn-Cox model. J. Phys. Oceanogr. 24:2560-76
Davis RE. 1998. Preliminary results from directly measuring mid-depth circulation in the tropical and South Pacific. J. Geophys. Res. 103:24619-39

Defant A. 1961. Physical Oceanography, Vol. 1. New York: Pergamon. 598 pp.

Dushaw BD, Cornuelle BD, Worcester PF, Howe BM, Luther DS. 1995. Barotropic and baroclinic tides in the central North Pacific Ocean determined from long-range reciprocal acoustic transmissions. J. Phys. Oceanogr. 25:631-47

Egbert GD, Ray RD. 2000. Significant dissipation of tidal energy in the deep ocean inferred from satellite altimeter data. Nature 405:775-78

Emanuel KA, Neelin JD, Bretherton CS. 1994. On large-scale circulation in convecting atmospheres. Q. J. R. Meteorol. Soc. 120:1111-43

Eriksen CC. 1985. Implications of ocean bottom reflection for internal wave spectra and mixing. J. Phys. Oceanogr. 15:1145-56

Faller AJ. 1968. Sources of energy for the ocean circulation and a theory of the mixed layer. Proc. 5th US Congr. Appl. Mech., ASME, Univ. Minn., Minneapolis, June 14-17, 1966, pp. 651-72

Ferrari R, Adcroft A. 2003. The energetics of the Boussinesq approximation. In preparation

Ferron B, Mercier H, Speer K, Gargett A, Polzin 
K. 1998. Mixing in the Romanche Fracture Zone. J. Phys. Oceanogr. 28:1929-48

Fofonoff NP. 1998. Nonlinear limits to ocean thermal structure. J. Mar. Res. 56:793-811

Frankignoul C, Müller P. 1979. Quasigeostrophic response of an infinite beta-plane ocean to stochastic forcing by the atmosphere. J. Phys. Oceanogr. 9:104-27

Fu L-L. 1981. Observations and models of inertial waves in the deep ocean. Rev. Geophys. Space Phys. 19:141-70

Fu L-L, Keffer T, Niiler P, Wunsch C. 1982. Observations of mesoscale variability in the western North Atlantic: A comparative study. J. Mar. Res. 40:809-48

Ganachaud A, Wunsch C. 2000. Improved estimates of global ocean circulation, heat transport and mixing from hydrographic datatransport. Nature 408:453-57

Gargett AE. 1989. Ocean turbulence. Аnnu. Rev. Fluid Mech. 21:419-51

Gargett AE, Holloway G. 1984. Dissipation and diffusion by internal wave breaking. J. Mar. Res. 42:15-27

Garrett C. 1979. Mixing in the ocean interior. Dyn. Atm. Oceans 3:239-65

Garrett C. 2001. What is the "near-inertial" band and why is it different from the rest of the internal wave spectrum? J. Phys. Oceanogr. 31:962-71

Garrett C, Maccready P, Rhines P. 1993. Boundary mixing and arrested Ekman layersrotating stratifed flow near a sloping boundary. Annu. Rev. Fluid Mech. 25:291323

Garrett C, Munk W. 1979. Internal waves in the ocean. Annu. Rev. Fluid Mech. 11:339-69

Garrett C, St. Laurent L. 2002. Aspects of deep ocean mixing. J. Oceanogr. 58:11-24

Gent PR, McWilliams JC. 1990. Isopycnal mixing in ocean circulation models. J. Phys. Oceanogr. 20:150-55

Gill AE. 1982. Atmosphere-Ocean Dynamics. New York: Academic. 662 pp.

Gill AE, Green JSA, Simmons AJ. 1974. Energy partition in the large-scale ocean circulation and the production of mid-ocean eddies. Deep-Sea Res. 21:499-528
Gille ST, Yale MM, Sandwell DT. 2000. Global correlation of mesoscale ocean variability with seafloor roughness from satellite altimetry. Geophys. Res. Lett. 27:1251-54

Gregg MC. 1987. Diapycnal mixing in the thermocline: a review. J. Geophys. Res. 92:524986

Gregg MC. 1989. Scaling turbulent dissipation in the thermocline. J. Geophys. Res. 94:9686-98

Gregg MC. 1998. Estimation and geography of diapycnal mixing in the stratified ocean. In Physical Processes in Lakes and Oceans, ed. J Imberger, pp. 305-38. Washington, DC: Am. Geophys. Union

Henyey FS, Wright J, Flatté SM. 1986. Energy and action flow through the internal wave field-an eikonal approach. J. Geophys. Res. 91:8487-95

Heywood KJ, Garabato ACN, Stevens DP. 2002 . High mixing rates in the abyssal Southern Ocean. Nature 415:1011-14

Hogg NG, Biscaye P, Gardner W, Schmitz WJ. 1982. On the transport and modification of Antarctic Bottom water in the Vema Channel. J. Mar. Res. 40(Suppl.):231-63

Hogg NG, Owens WB. 1999. Direct measurement of the deep circulation within the Brazil Basin. Deep-Sea Res. Part 2, 46:335-53

Huang RX. 1998. On the balance of energy in the oceanic general circulation. Sci. Atmos. Sin. 22:562-74

Huang RX. 1999. Mixing and energetics of the oceanic thermohaline circulation. J. Phys. Oceanogr. 29:727-46

Huang RX, Wang W. 2003. Gravitational potential energy sinks/sources in the oceans. Submitted

Iselin CO'D. 1939. The influence of vertical and lateral turbulence on the characteristics of the waters at mid-depths. Trans. Am. Geophys. Union 20:414-17

Jayne SR, St. Laurent LC. 2001. Parametrizing tidal dissipation over rough topography. Geophys. Res. Lett. 28:811-14

Jeffreys HW. 1925. On fluid motions produced by differences of temperature and humidity. Q. J. R. Meteorol. Soc. 51:347-56 
Kantha LH, Tierney CC. 1997. Global baroclinic tides. Prog. Oceanogr. 40:163-78

Karsten RH, Jones H, Marshall J. 2002. The role of eddy transfer in setting the stratification and transport of a circumpolar current. J. Phys. Oceanogr. 32:39-54

Khatiwala S. 2003. Generation of internal tides in an ocean of finite depth: analytical and numerical calculations. Deep-Sea Res. 50:321

Kunze EK, Rosenfeld K, Carter GS, Gregg MC. 2002. Internal waves in Monterey Submarine Canyon. J. Phys. Oceanogr. 32:1890-913

Large WG, Nurser AJG. 2001. Ocean surface water mass transformation. See Siedler et al. 2001, pp. 317-36

Ledwell JR, Hickey BM. 1995. Evidence for enhanced boundary mixing in the SantaMonica Basin. J. Geophys. Res. 100:2066579

Ledwell JR, Montgomery ET, Polzin KL, St. Laurent LC, Schmitt RW, Toole JM. 2000. Evidence for enhanced mixing over rough topography in the abyssal ocean. $\mathrm{Na}$ ture 403:79-182

Ledwell JR, Watson AJ, Law CS. 1998. Mixing of a tracer in the pycnocline. J. Geophys. Res. 103:21499-529

Lefevre J-M, Cotton PD. 2001. Ocean surface waves. In Satellite Altimetry and Earth Sciences, ed. L-L Fu, A Cazenave, pp. 305-28. San Diego: Academic

Legg SA, Adcroft A. 2003. Internal wave breaking at concave and convex slopes. J. Phys. Ocean 33: In press

Llewellyn-Smith SG, Young WR. 2002. Conversion of the barotropic tide. J. Phys. Oceanogr. 32:1554-66

Lueck R, Reid R. 1984. On the production and dissipation of mechanical energy in the ocean. J. Geophys. Res. 89:3439-45

Marotzke J, Scott JR. 1999. Convective mixing and the thermohaline circulation. J. Phys. Oceanogr. 29:2962-70

Marshall J, Schott F. 1999. Open-ocean convection: observations, theory and models. Rev. Geophys. 37:1-64

McDougall T. 1987. Thermobaricity, cabelling and water-mass conversion. J. Geophys. Res. 92:5448-64

Müller P, Holloway G, Henyey F, Pomphrey N. 1986. Nonlinear interactions among internal gravity waves. Rev. Geophys. 24:493536

Munk W. 1966. Abyssal recipes. Deep-Sea Res. 13:707-30

Munk W. 1981. Internal waves and small-scale processes. In Evolution of Physical Oceanography. Scientific Surveys in Honor of Henry Stommel, ed. BA Warren, C Wunsch, pp. 264-91. Cambridge: MIT Press

Munk W. 1997. Once again: once again-tidal friction. Prog. Oceanogr. 40:7-35

Munk W, Wunsch C. 1998. Abyssal recipes II: energetics of tidal and wind mixing. DeepSea Res. 45:1976-2009

Olbers D, Wenzel MJ, Willebrand J. 1985. The inference of North Atlantic circulation patterns from climatological hydrographic data. Rev. Geophys. 23:313-56

Oort AH, Anderson LA, Peixoto P. 1994. Estimates of the energy cycle of the oceans. $J$. Geophys. Res. 99:7665-88

Osborn TR. 1980. Estimates of the local rate of vertical diffusion from dissipation measurements. J. Phys. Oceanogr. 10:83-89

Osborn TR, Cox CS. 1972. Oceanic fine structure. Geophys. Fluid Dyn. 3:321-45

Paparella F, Young WR. 2002. Horizontal convection is non-turbulent. J. Fluid Mech. 466:205-14

Pedlosky J. 1987. Geophysical Fluid Dynamics, 2nd ed. Springer-Verlag. 710 pp.

Pedlosky J. 1996. Ocean Circulation Theory. Berlin: Springer-Verlag. 450 pp.

Peltier WR, Caulfield CP. 2003. Mixing efficiency in stratified shear flows. Annu. Rev. Fluid Mech. 35:135-67

Petruncio ET, Rosenfeld LK, Paduan JD. 1998. Observations of the internal tide in Monterey Canyon. J. Phys. Oceanogr. 28:1873-903

Phillips OM. 1977. The Dynamics of the Upper Ocean. Cambridge, UK: Cambridge Univ. Press. 336 pp. 2nd ed.

Phillips OM, Shyu JH, Salmun H. 1986. An experiment on boundary mixing — mean 
circulation and transport rates. J. Fluid Mech. 173:473-89

Polzin KL, Toole JM, Ledwell JR, Schmitt RW. 1997. Spatial variability of turbulent mixing in the abyssal ocean. Science 276:93-96

Ponte RM. 1994. Understanding the relation between wind- and pressure-driven sea level variability. J. Geophys. Res. 99:8033-40

Price JF, Baringer MO. 1994. Outflows and deep-water production by marginal seas. Prog. Oceanogr. 33:161-200

Roemmich D, Hautala S, Rudnick D. 1996. Northward abyssal transport through the Samoan Passage and adjacent regions. $J$. Geophys. Res. 101:14039-55

Rossby HT. 1965. On thermal convection driven by non-uniform heating from below: an experimental study. Deep-Sea Res. 12:9-16

Rossby T. 1998. Numerical experiments with a fluid heat non-uniformly from below. Tellus A 50:242-57

Rudnick DL, Boyd TJ, Brinard RE, Carter GS, Egbert GD. 2003. From tides to mixing along the Hawaiian Ridge. Science 301:355-57

Samelson RM, Vallis GK. 1997. Large-scale circulation with small diapycnal diffusion: the two thermocline limit. J. Mar. Res. 55:223-75

Sandström JW. 1908. Dynamicsche Versuche mit Meerwasser. Ann. Hydrogr. Martimen Meteorol. 36:6-23

Sandström JW. 1916. Meteorologische Studien in Schwedischen Hochgebirge. Goteborgs Kungl. Vensk. Vitterh.-Samh. Handingar 27:1-48

Saunders PM. 1987. Flow through Discovery Gap. J. Phys. Oceanogr. 17:631-43

Scott JR, Marotzke J, Adcroft A. 2001. Geothermal heating and its influence on the meridional overturning circulation. J. Geophys. Res. 106:31141-54

Siedler G, Church J, Gould J, eds. 2001. Ocean Circulation and Climate: Observing and Modeling the Global Ocean. San Diego: Academic. 715 pp.

St. Laurent L, Garrett C. 2002. The role of internal tides in mixing the deep ocean. J. Phys. Oceanogr. 32(10):2882-99
St. Laurent LC, Toole JM, Schmitt RW. 2001. Buoyancy forcing by turbulence above rough topography in the Brazil Basin. J. Phys. Oceanogr. 31:3476-95

Stammer D, Böning CW, Dieterich C. 2001. The role of variable wind forcing in generating eddy energy in the North Atlantic. Prog. Oceanogr. 48:289-311

Stammer D, Wunsch C, Ponte R. 2000. Dealiasing global altimetric records with a general circulation model. Geophys. Res. Lett. 27:1175-78

Staquet C, Sommeria J. 2002. Internal gravity waves: from instabilities to turbulence. Anпu. Rev. Fluid Dyn. 34:559-93

Stern ME. 1975. Ocean Circulation Physics. New York: Academic. 246 pp.

Stommel H. 1961. Thermohaline convection with two stable regimes of flow. Tellus 13:131-49

Stommel H, Arons AB. 1960. On the abyssal circulation of the world ocean-II. An idealized model of the circulation pattern and amplitude in oceanic basins. Deep-Sea Res. 6:217-33

Tandon A, Garrett C. 1996. On a recent parameterization of mesoscale eddies. J. Phys. Oceanogr. 26:406-11

Thorpe SA. 2001. On the reflection of internal wave groups from sloping topography. $J$. Phys. Oceanogr. 31:3121-26

Toggweiler JR, Samuels B. 1998. On the ocean's large scale circulation in the limit of no vertical mixing. J. Phys. Oceanogr. 28: 1832-52

Toole JM, McDougall TJ. 2001. Mixing and stirring in the ocean interior. See Siedler et al. 2001, pp. 337-56

Toole JM, Polzin KL, Schmitt RW. 1994. Estimates of diapycnal mixing in the abyssal ocean. Science 264(5164):1120-23

Townsend AA. 1965. Excitation of internal waves by a turbulent boundary layer. J. Fluid Mech. 22:241-52

Turner JS. 1973. Buoyancy Effects in Fluids. Cambridge, UK: Cambridge Univ. Press. 367 pp.

Visbeck M, Marshall J, Haine T, Spall M. 1997. 
On the specification of eddy transder coefficients in coarse resolution ocean circulation models. J. Phys. Oceangr. 27:381-402

Warren BA. 1981. Deep circulation of the world ocean. In Evolution of Physical Oceanography. Scientific Surveys in Honor of Henry Stommel, ed. BA Warren, C Wunsch, pp. 641. Cambridge, MA: MIT Press

Webb DJ, Suginohara N. 2001. Oceanography: Vertical mixing in the ocean. Nature 409: 37

Welander P. 1971. The thermocline problem. Philos. Trans. R. Soc. London Ser. A 270:6973

Winters KB, D'Asaro EA. 1996. Diascalar flux and the rate of fluid mixing. J. Fluid. Mech. 317:179-83

Winters KB, Lombard PN, Riley JJ, D'Asaro EA. 1995. Available potential energy and mixing in density-stratified fluids. J. Fluid Mech. 289:115-28

Winton M. 1995. Why is the deep sinking narrow? J. Phys. Oceanogr. 25:997-1005
Wuest A, Lorke A. 2003. Small-scale hydrodynamics in lakes. Annu. Rev. Fluid Mech. 35:373-412

Wunsch C. 1975. Internal tides in the ocean. Rev. Geophys. Space Phys. 13:167-82

Wunsch C. 1997. The vertical partition of oceanic horizontal kinetic energy. J. Phys. Oceanogr. 27:1770-94

Wunsch C. 1998 . The work done by the wind on the oceanic general circulation. J. Phys. Oceanogr. 28:2332-40

Wunsch C. 2002a. Ocean observations, the climate forecast problem. In Meteorology at the Millennium, ed. RP Pearce, pp. 233-45. London: Academic

Wunsch C. 2002b. What is the thermohaline circulation? Science 298:1180-81

Wunsch C, Stammer D. 1997. Atmospheric loading and the "inverted barometer" effect. Rev. Geophys. 35:79-107

Zang X, Wunsch C. 2001. Spectral description of low frequency oceanic variability. J. Phys. Oceanogr. 31:3073-95 
Pacific 150W (10-11/92) Gamma-N (CTD)

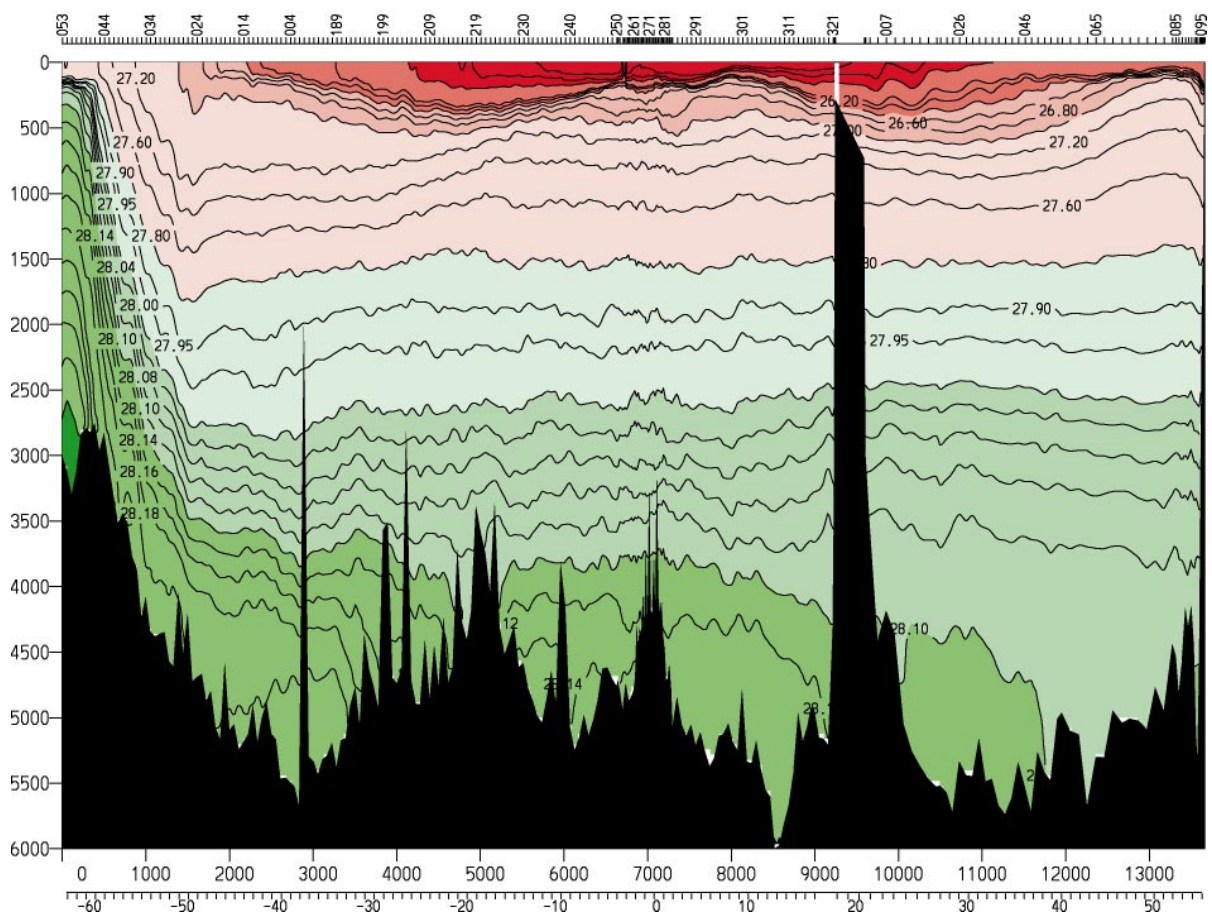

Figure 1 Potential density surfaces, $\sigma$, in $\mathrm{kg} / \mathrm{m}^{3}$ along a section running down the central Pacific Ocean from Antarctica to the Aleutians (WOCE Section P16). Numerical values are $(\sigma-1000) \times 10^{3}$. [Technically, these are so-called neutral surfaces (McDougall 1987), which differ slightly from the conventional density to accommodate problems arising from the nonlinear equation of the state of sea water. For present purposes, the difference from true density is immaterial.] 